\title{
فن الجداريات : أصولة وتقنياته
}

إعداد

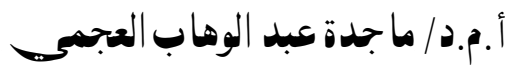

أستاذ الأشغال الفنية والشعبية المساعد

كلية التربية النوعية - جامعة المنصورة

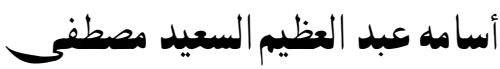

$$
\text { كلية التربية النوعية - جامعة المنصورة التربية الفنية }
$$

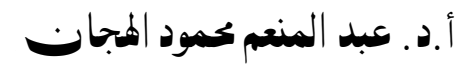

أستاذ أشغال الخشب المتفرغ

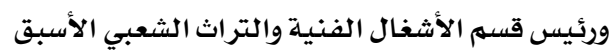

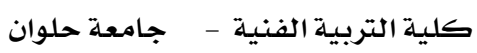

$$
\begin{aligned}
& \text { م/إبر|هيم أحمد أحمد السيد } \\
& \text { مدرس النحت بقسم التربية الفنية } \\
& \text { كلية التربية النوعية - جامعة المنصورة }
\end{aligned}
$$

مجلة بحوث التزبية النوعية - جامعة المنصورة

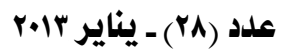

* بحث مستل من رسالة دكتوراه - كلية التربية النوعية - جامعة المنصورة 


\section{فن البداريات : أصولة وتقنياته}

إعداد
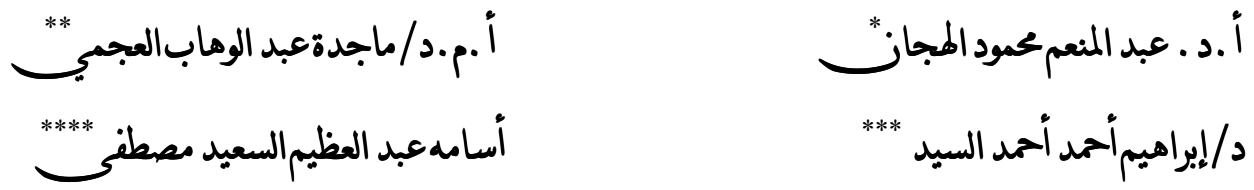

مقدمة : مقة

يعد الفن الجداري أو الجداريات كما اصطلح عليها واحدة من حقول الفن التشكيلي والتي كان لها انتشارا كبيرا يِّ التاريخ قديها وحديثا مرت خلالها بمراحل كثيرة حيث كانت للعقيدة

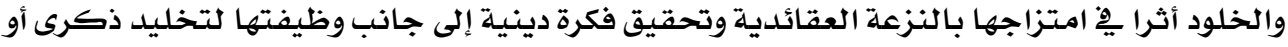

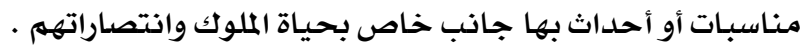
ولقد جاءت الجدارية مند القدم معبرة عن واقع الإنسان ووجدانه ، وتطورت مـع تطور حياتهـ

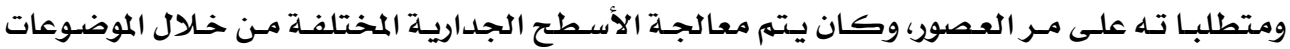

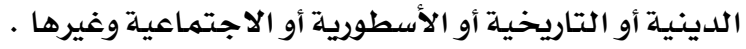
نشأة وتطور الفن الجداري عبر الهصور الإختلفة :

فن الجداريات مـن أقدم الفنون التي عرفها الإنسـان منـذ فجر التاريخ ، كهما أنـه يعـد أول لغـة

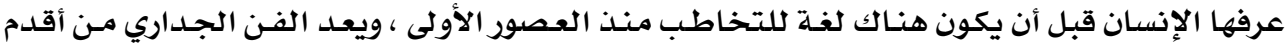

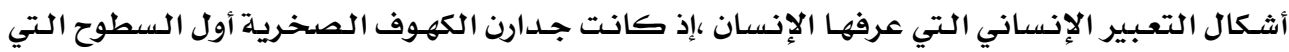

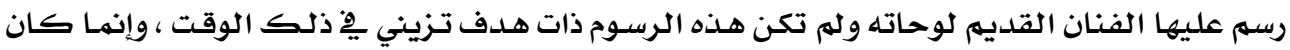

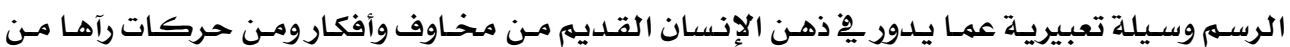

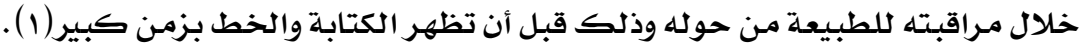
ومسع مـرور الـزمن تطـورت حيـاة الإنسان وتطـور معهـا فن الرسـهم الجــاري بتطـور الخامـات

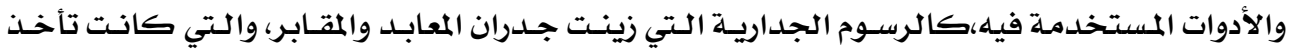

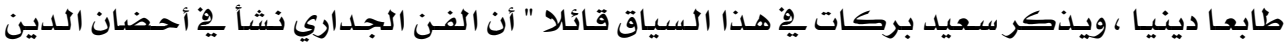

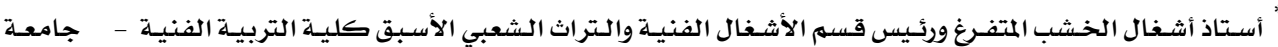
حلوان

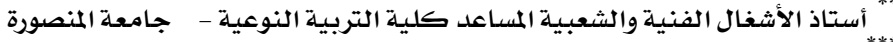

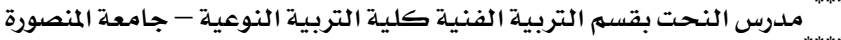

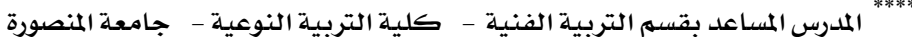

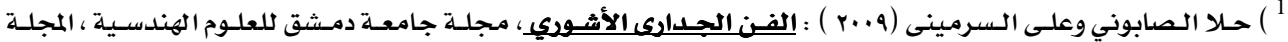

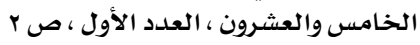




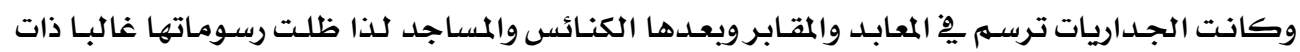

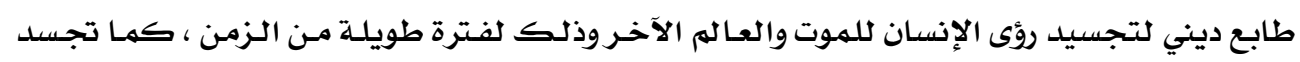

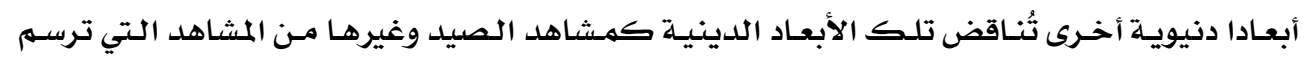

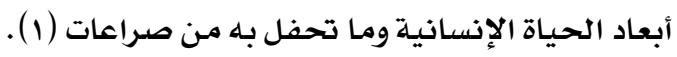

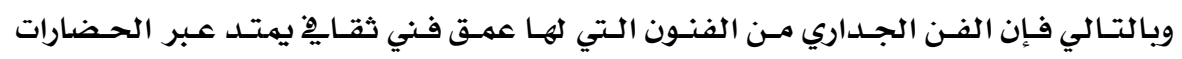

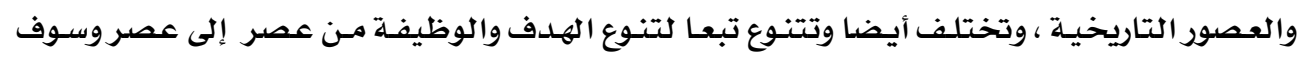

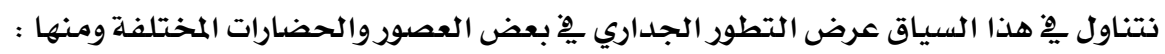

$$
\begin{aligned}
& \text { 1. جداريات العصر البدائي. } \\
& \text { r. r. جداريات الفن المصري القديه. } \\
& \text { r. ب. جـاريات الفن الأثوري. } \\
& \text { ع. جـ جداريات الفن القبطي. } \\
& \text { ه. جداريات الفن الإسـلامي. } \\
& \text { 7. } \\
& \text { V. جداريات العصر الحديث. } \\
& \text { اـ جداريات العصر البدائي : }
\end{aligned}
$$

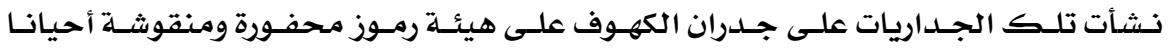

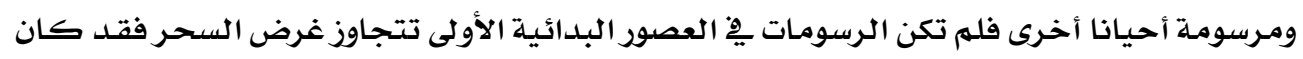

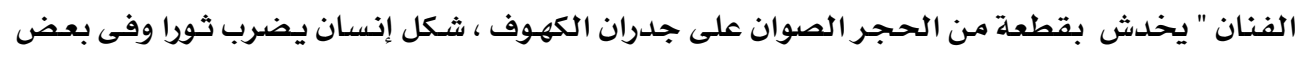

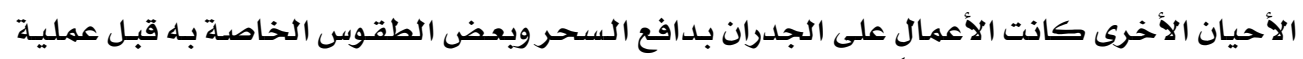

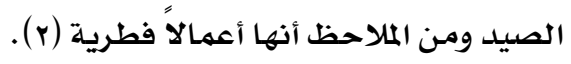

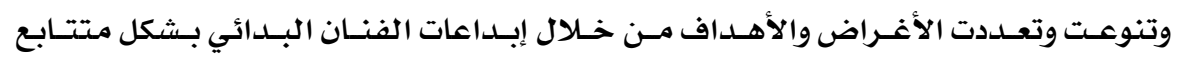

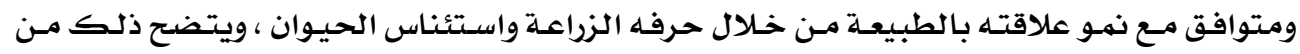

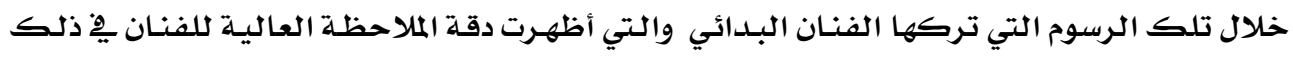

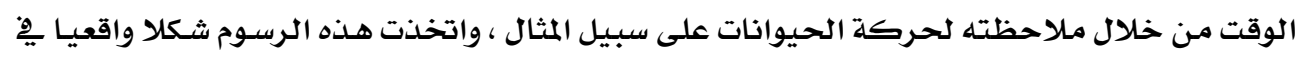

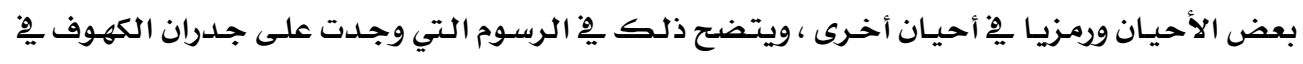

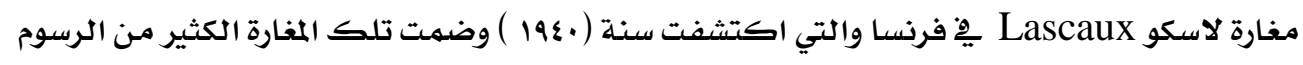

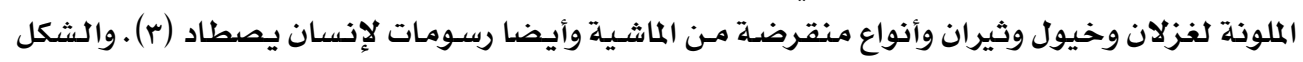

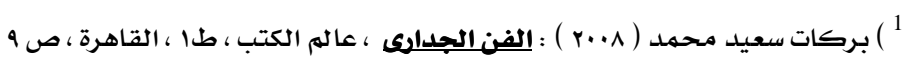

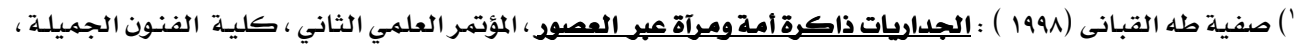

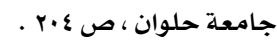

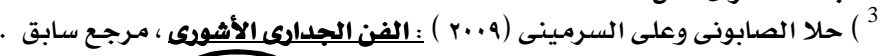




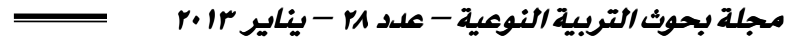

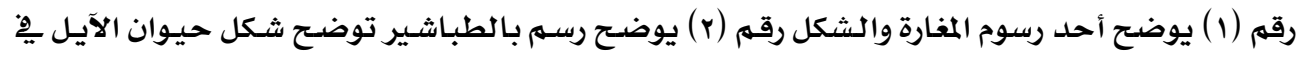
كهف فان دى جوم بفرنسا .

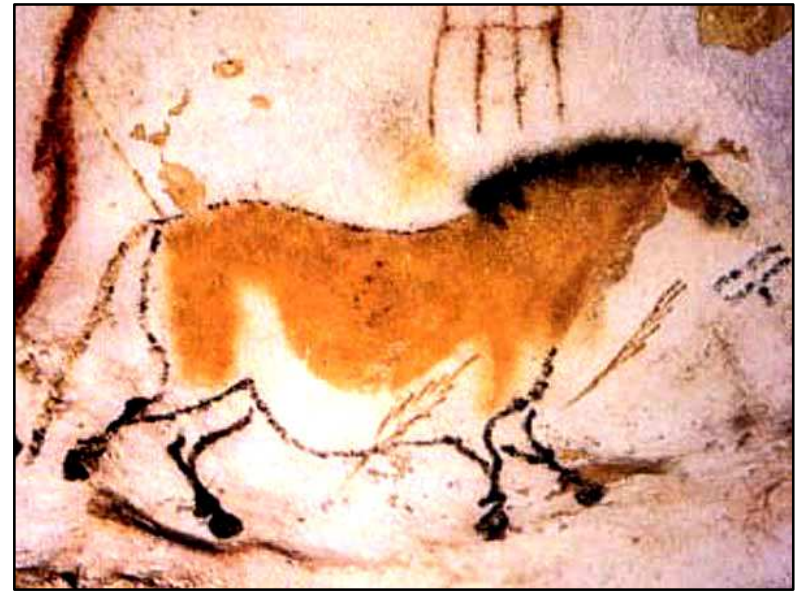

شكل رقم (1)(1) (1) (1)

أحد رسوم مغارة لاسكو بفرنسا

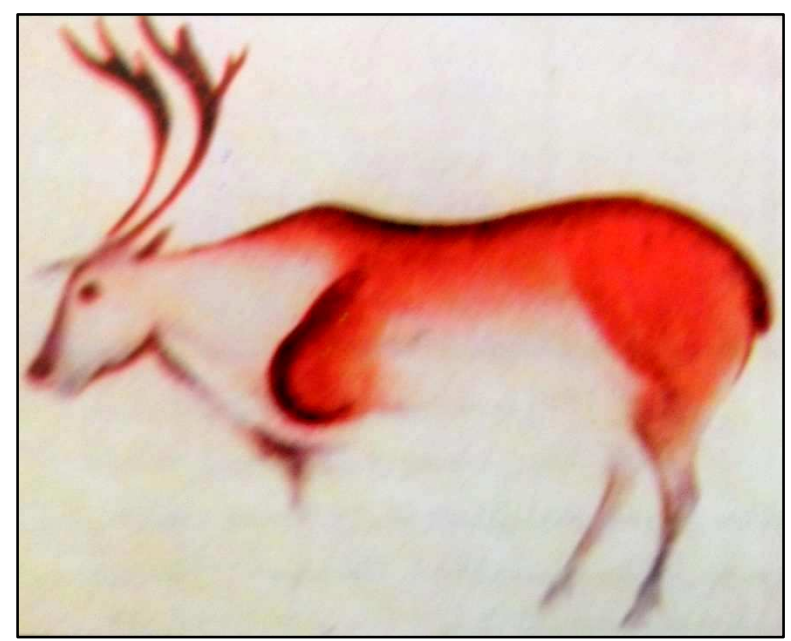

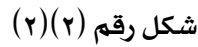

رسم بالطباشير والأحبار الملونة

من كهف "فان دى جوم" بفرنسا

$\left.{ }^{2}\right)$ http://en.wikipedia.org/wiki/Lascaux.

2) بركات سعيد محمد ( (r... ) : الفن الجدارى ، مرجع سابق ، ص ه(ملحق الصور). 


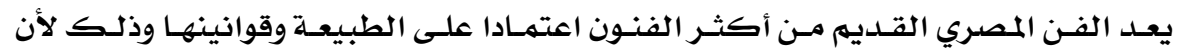

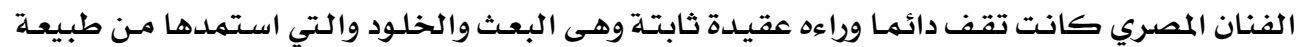

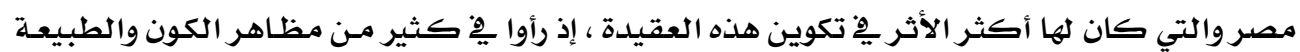

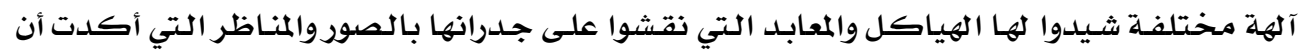

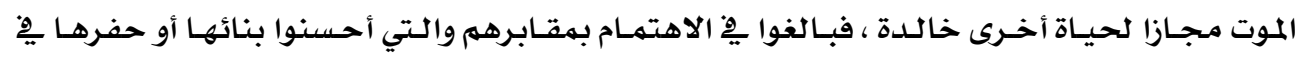

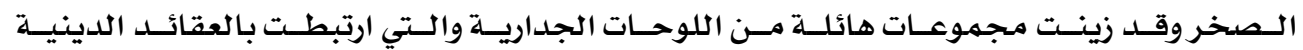

(1). والجنائزيـة

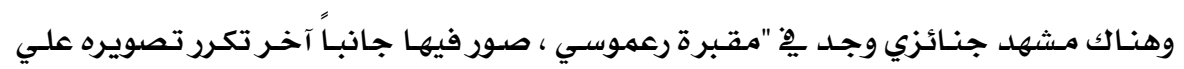

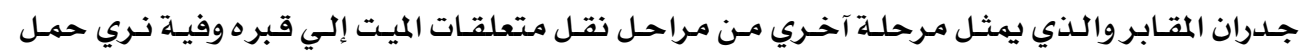

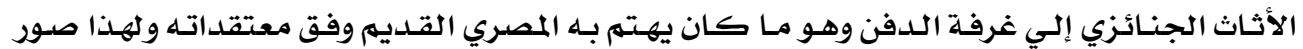

ذلك علي جلدران المقابر لتذكرة فِ حياته الأخرى عند عودته للحياة مرة ثانية (r) شكل رقهم (r) .

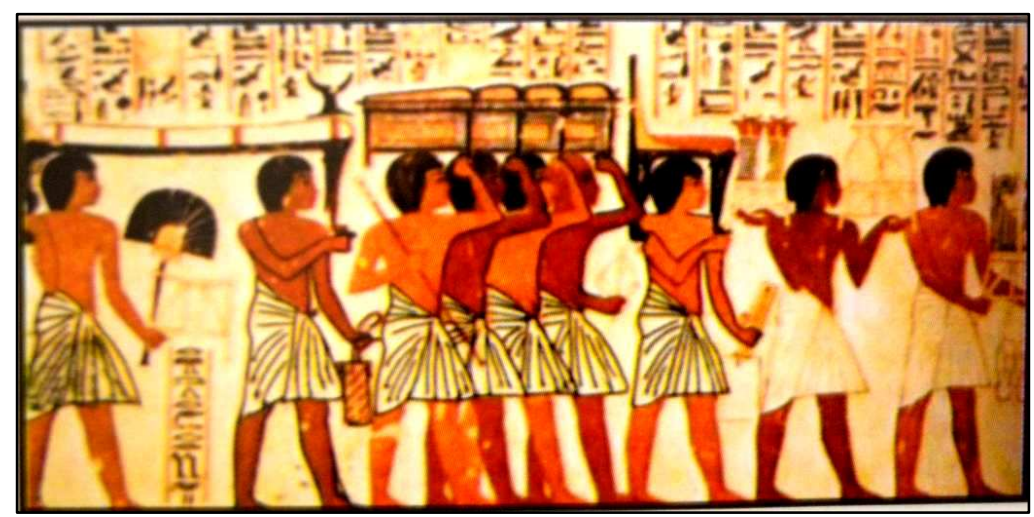

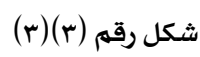

لوحة جداريه تمثل حملة الأثاث الجنائزي والمرافقين للنعش من مقبرة رعموسي،طيبة.

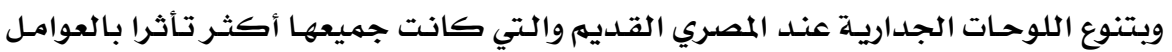

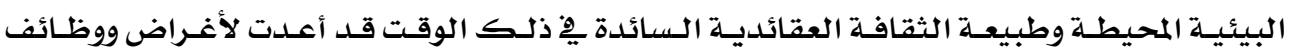

متعدددة ومنها :

1 ) محمد أنور شكرى (1994 ) : الفن المصرى القديم منذ اقدمعصوره حتى نهاية الدولة القدبية ، الهيئة العامة المصرية للكتاب ، ص ع ع ، 0

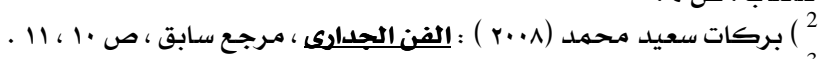




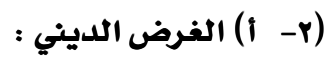

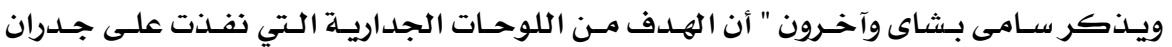

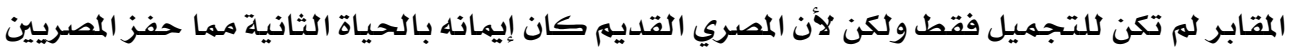

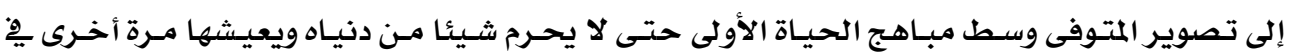

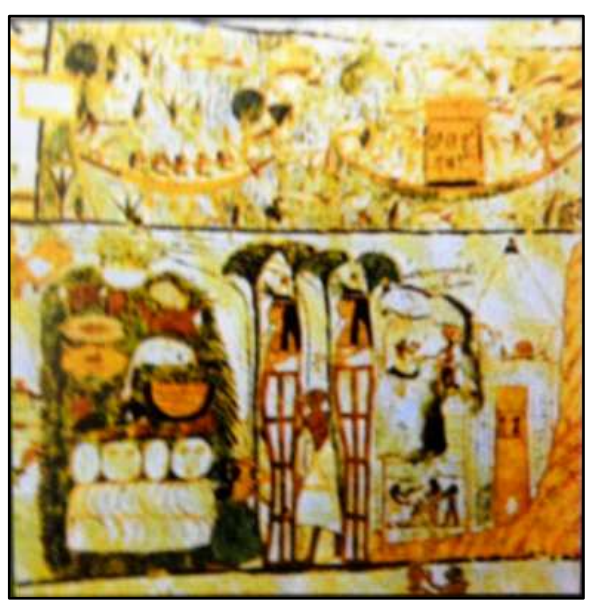

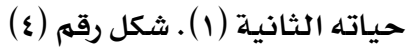

شكل رقم (飞)

لوحة جداريه تمثل رحلة المتوقي الجنائزية وتطهير

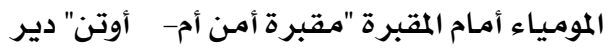

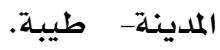

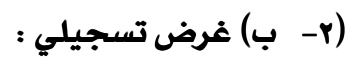

وفى هذا الغرض تكون تلك الجـداريات " منفـذة على بنـاء ضـخم يـراه ويعرفه الجميـع ، لـذا

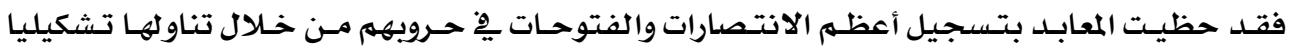

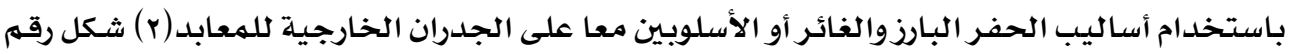

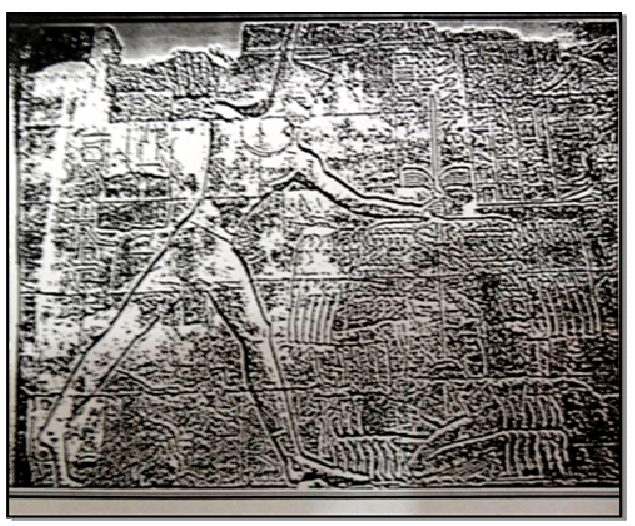

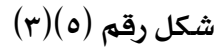

جداريه توضح أجمل نقوش معبد هابو المنحوتة

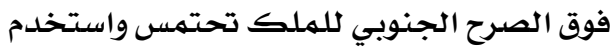

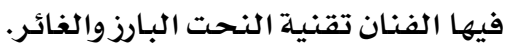

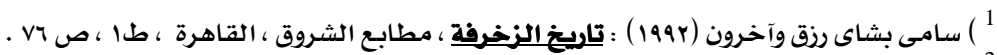

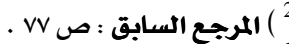

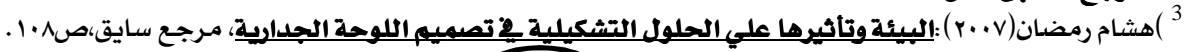




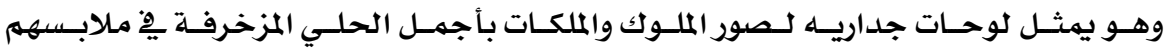

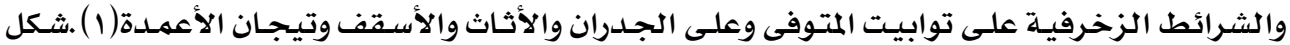

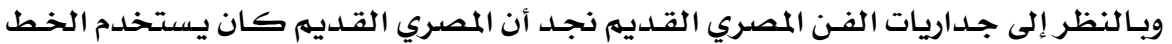

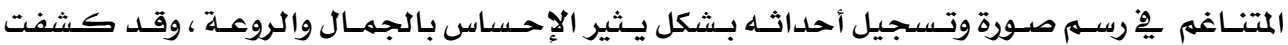

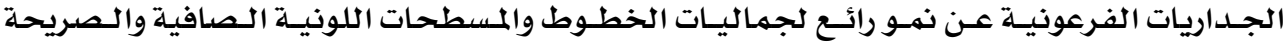

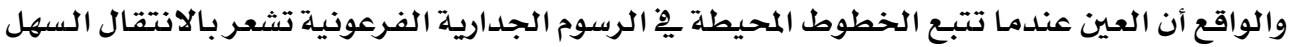

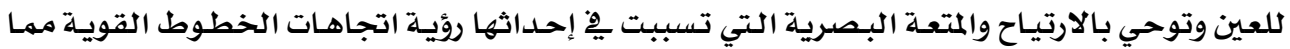

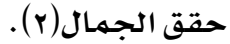

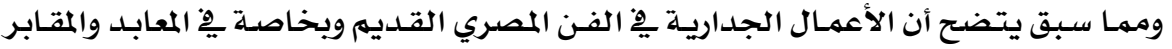

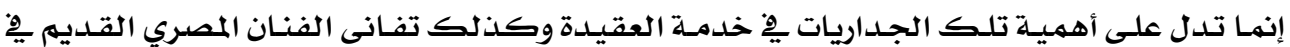

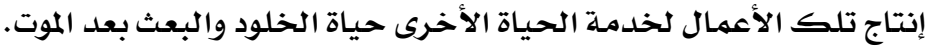

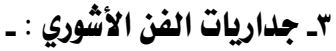

بني الآثوريون عاصمتهم الأولى ( آثور ) نسبة إلى كبير ألهتهم (آشور) إله الشمس واستقر

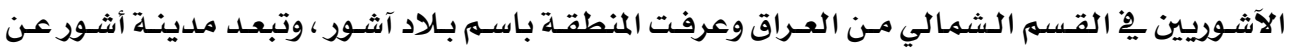

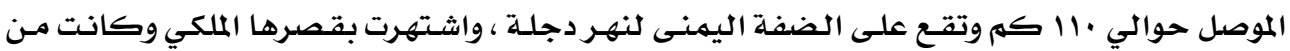

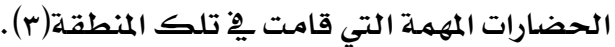

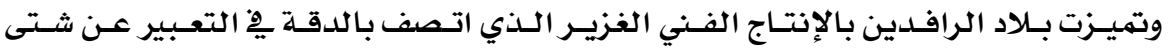

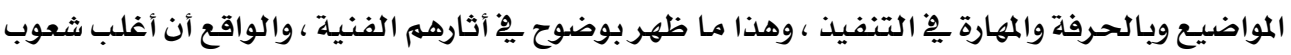

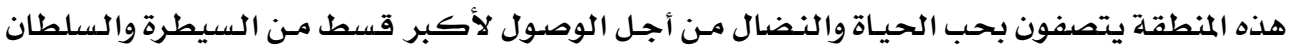

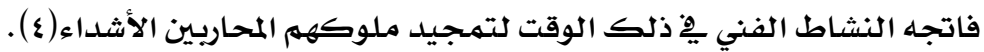

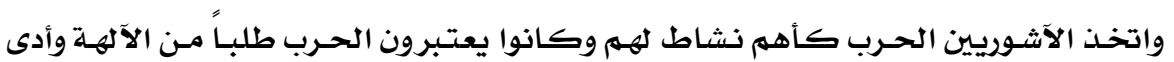

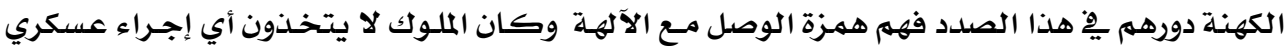

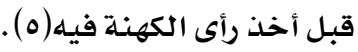

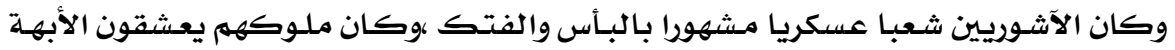
والفخامـة وتخصص الفن الأشوري يِّ الشئون الملكيـة الخاصـة ، فالقصور الملكيـة الضخمـة تحمل آثار

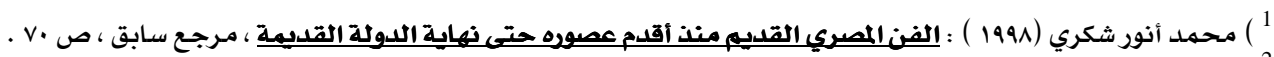

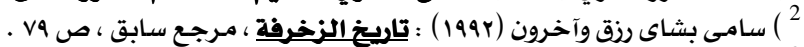

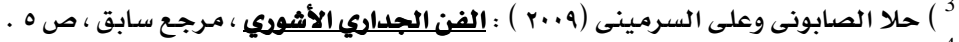

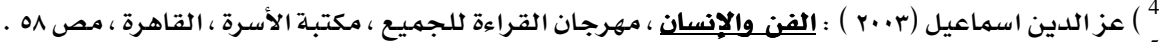

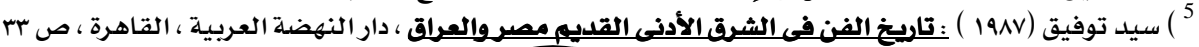


العظمـة والجاه وعلى جدرانها صور لحياتهم المعتادة والتي كانوا يقضونها يْ الحرب والصيد ، ويظهر

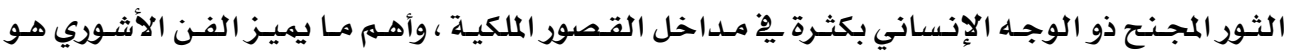

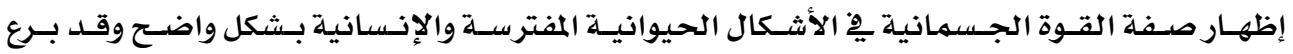

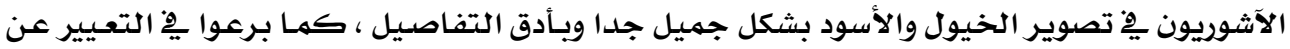

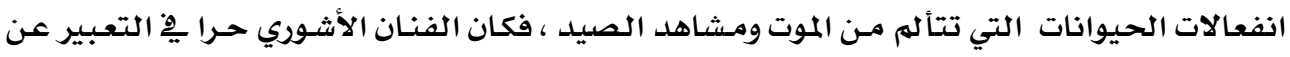

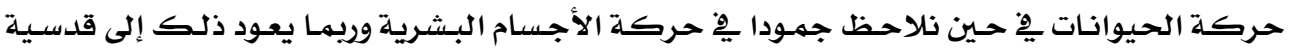

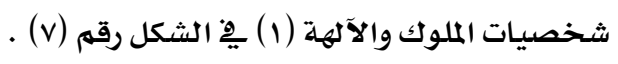

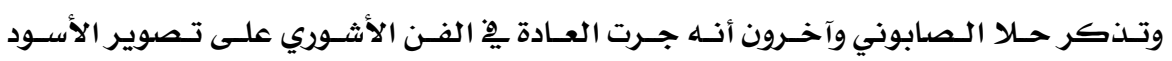

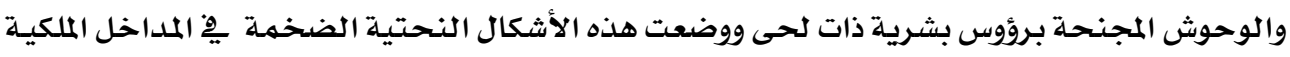

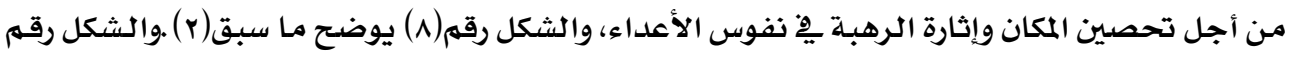

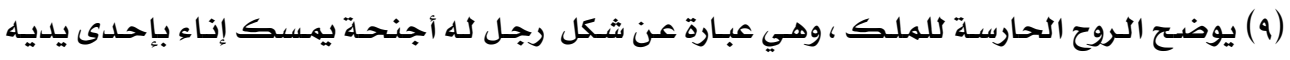

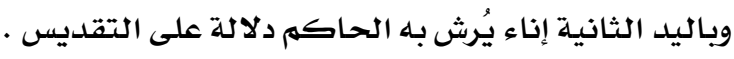

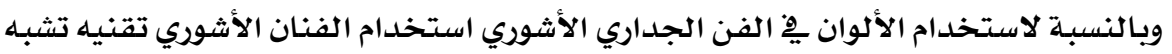

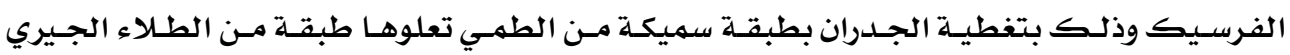

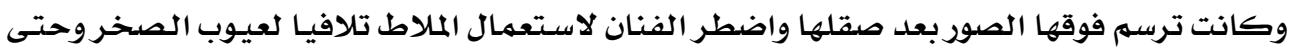

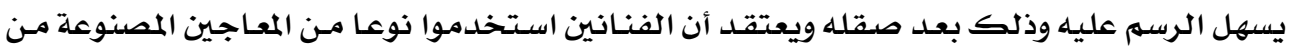

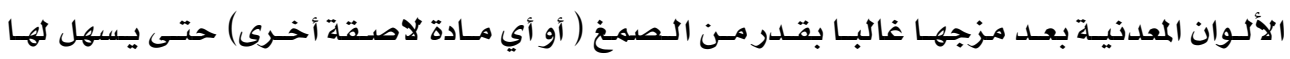

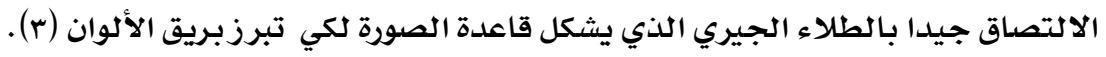

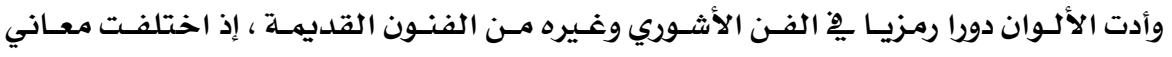

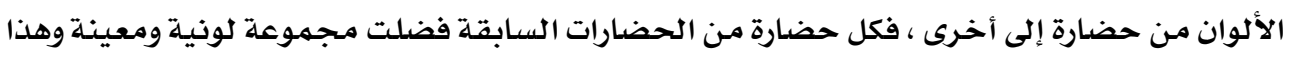

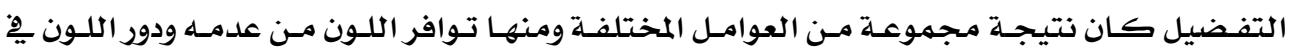

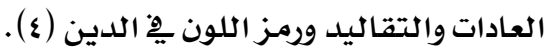

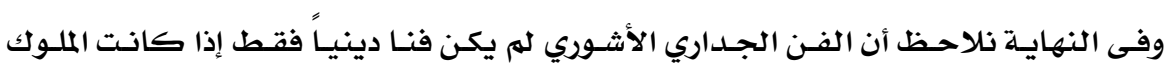

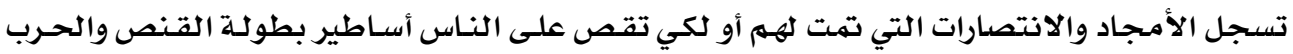

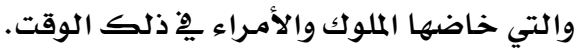

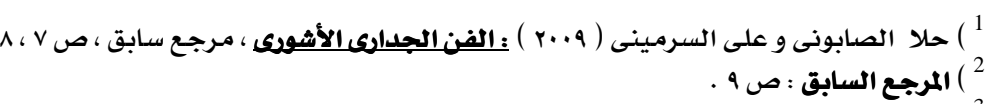

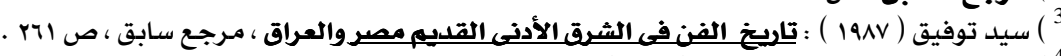

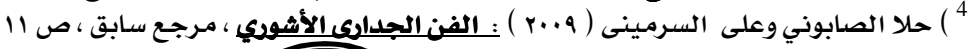




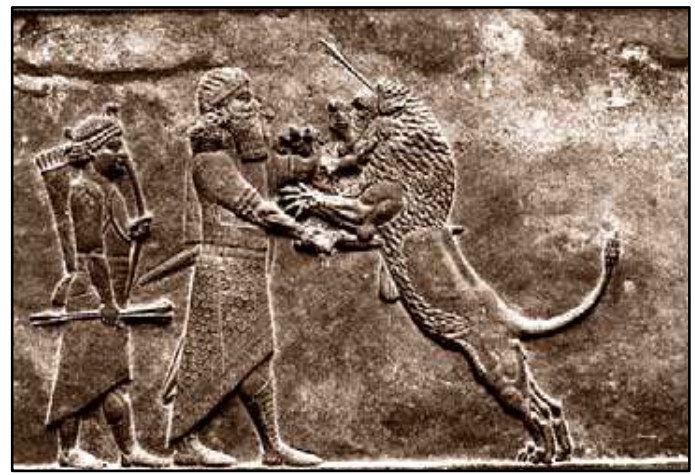

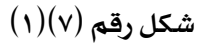

نحت آشوري (الملك يطعن أسدا).

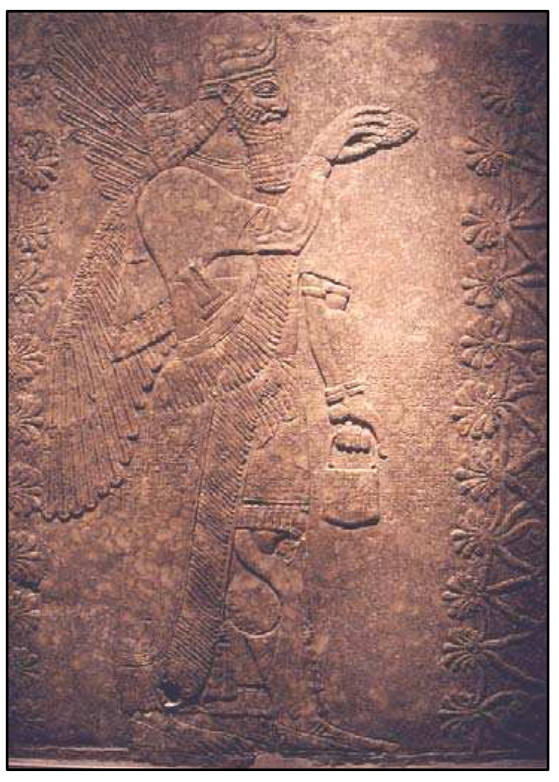

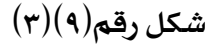

نحت آشوري يمثل الروح الحارسة للملك.

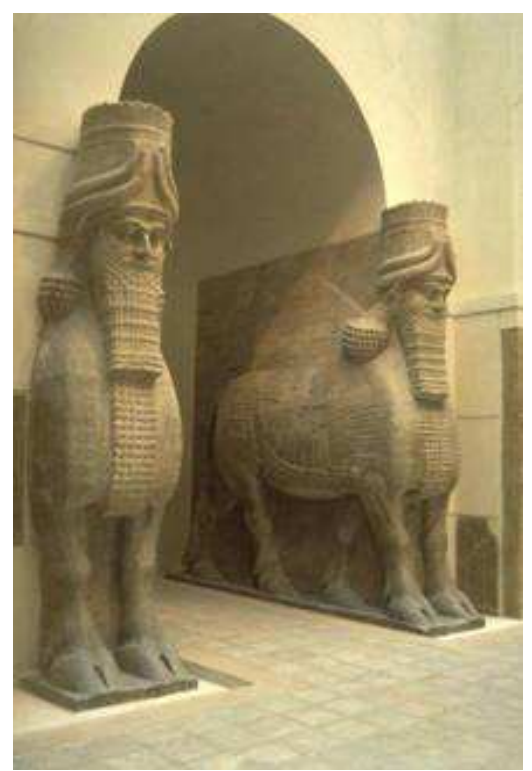

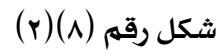

نحت آشوري يمثل الثور المجنح.

1) WWW_ancientreplicas_com-kingstabbing, lion_jpg.mht

${ }^{2)}$ www.tronchin.com.

3) حلا الصابوني وعلى السرمينى ( . . r ) : الفن الجدارى الأشوري ، مرجع سابق ، ص • 1. 


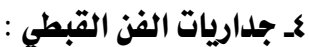

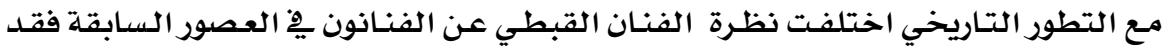

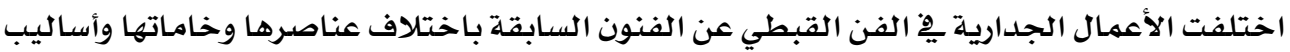

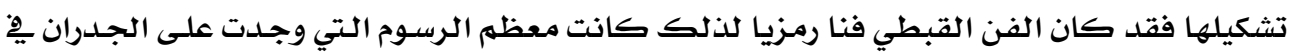

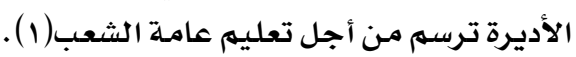

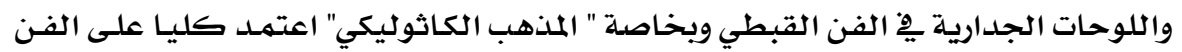

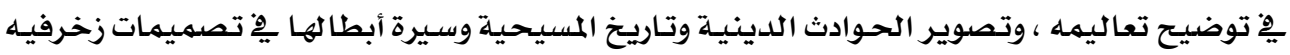

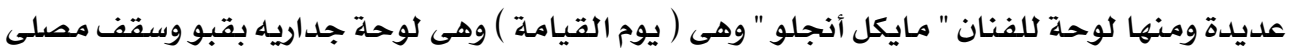

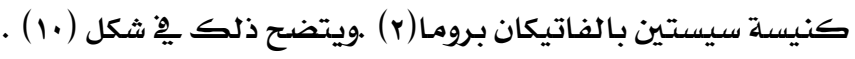

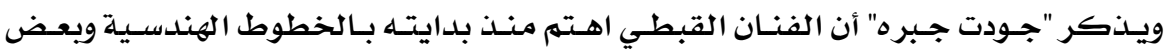

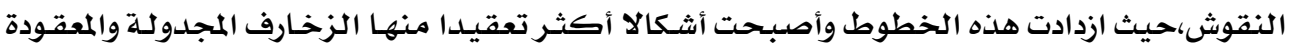

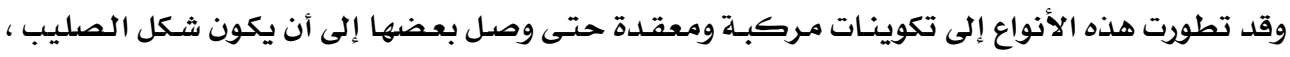

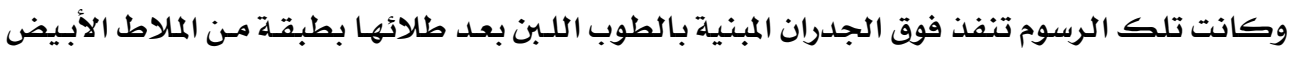
اللون أو الجص (r) (r). وأصبحت الأعمال الجدارية يِّ الفن القبطي جزءا أساسيا للتأكيد على الأهـداف الروحيـة

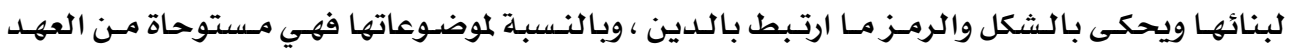

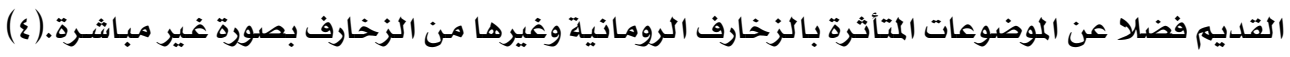

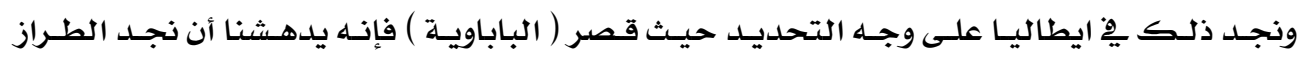

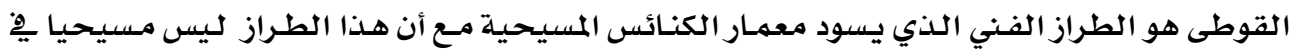

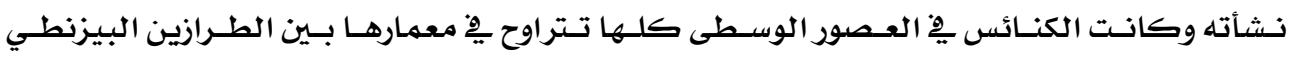
والقوطى(0)

وهناك العديد من اللوحات الجداريـة القبطيـة والتي تخـدم الدين بشكل واضـح ومنهـا لوحسة

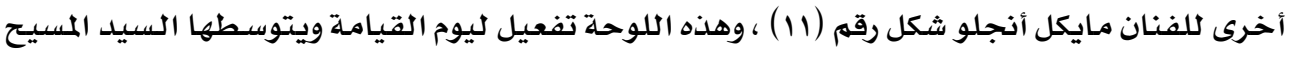

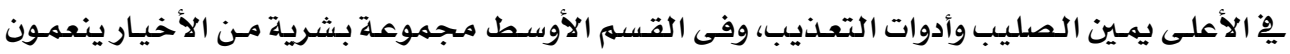

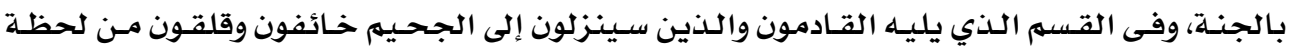

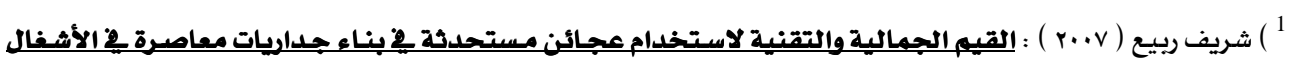

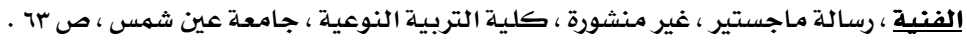

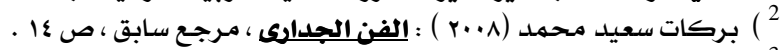

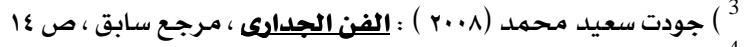

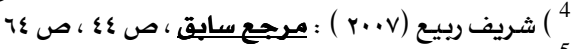

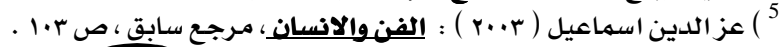


انتظارهم الجحيه ، وهذه اللوحة لها طابع زخـرِِ جـاري بـديع ورائسع حيث يحكى قصة الخير والشر

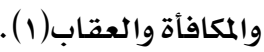

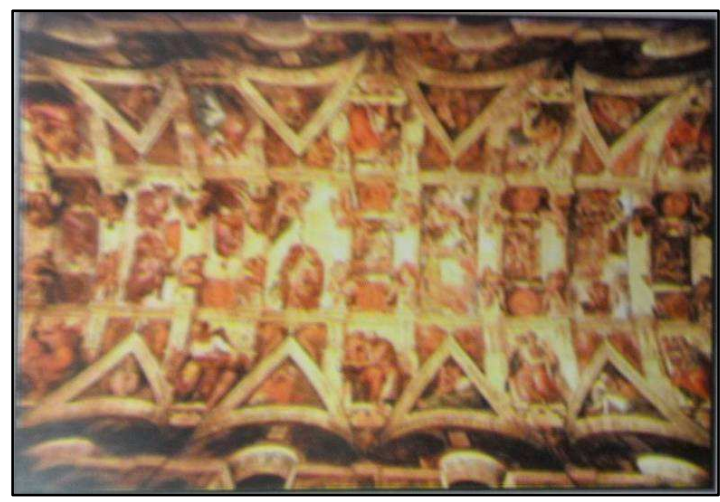

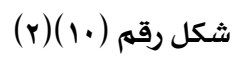

لوحة يوم القيامة للفنان مايكل انجلو بسقف كنيسـة سيستين بروما.

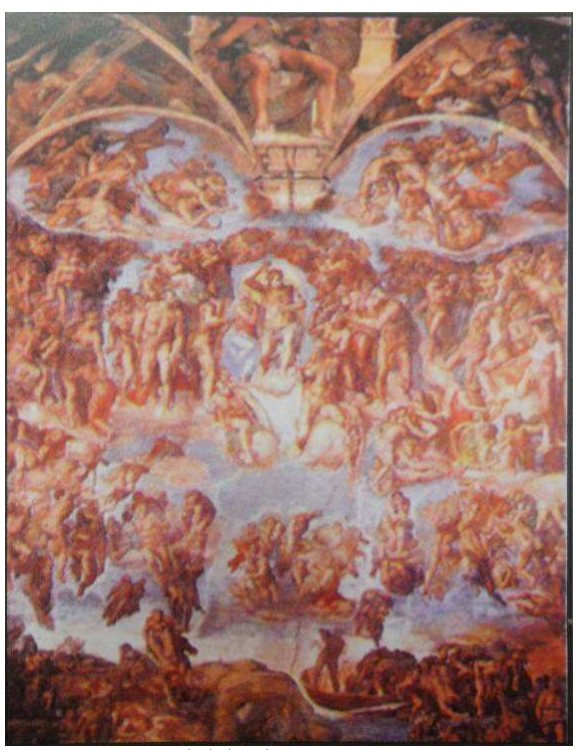

شكل رقم (11)(ب) (11)

تفصيل للوحة يوم القيامـة لمايكل أنجلو يوضح مجموعات البشر تمثل مواقف مختلفة.

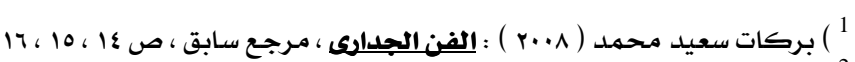

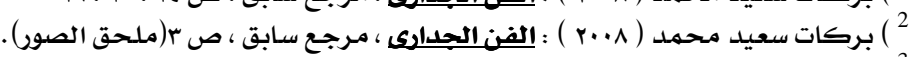
3 ) المرجع السابق:ص ع (ملحق الصور). 


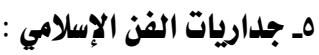

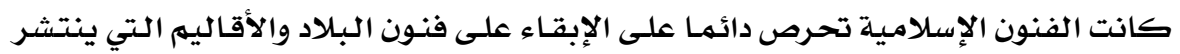

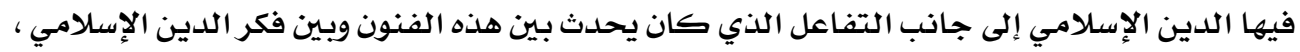

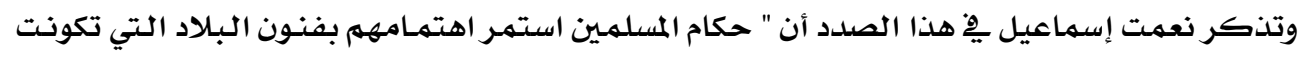

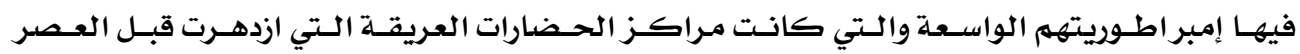

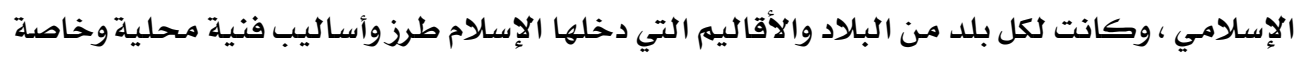

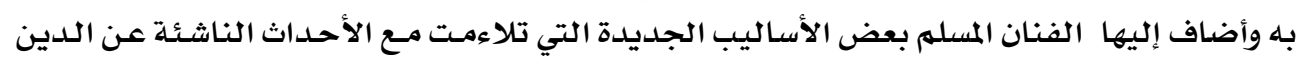

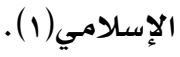

وقد نتج عما سبق امتزاج الفن الإسـلامي بفنـون تلك البـلاد التي فتحهـا الإسـلام وأدى هـذا

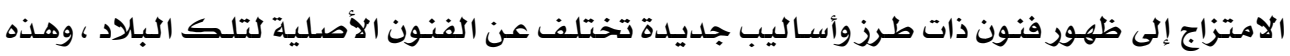

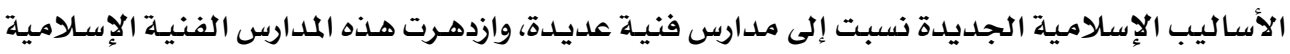

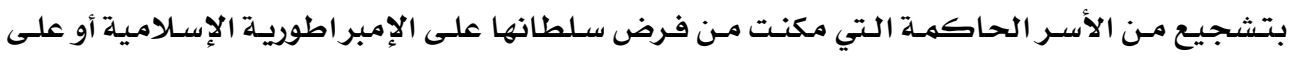

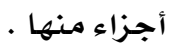

ومن الفنون الإسلاميلة التي ازدهرت فى العصر الإسلامي فن الجداريات، واشتملت الجداريات

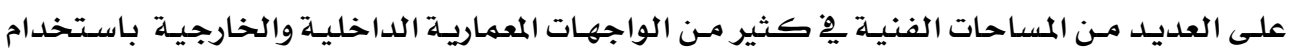

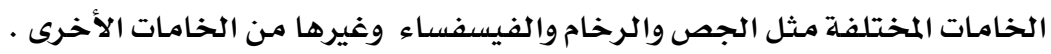

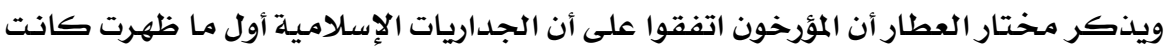

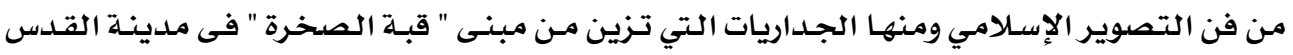

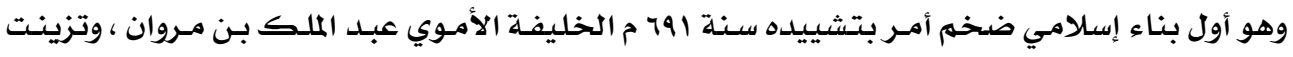

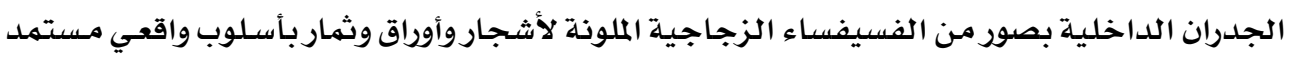

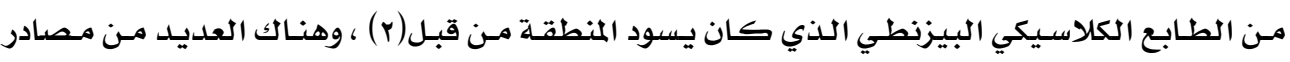

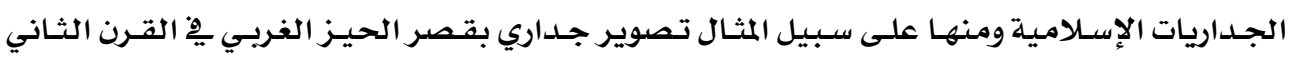

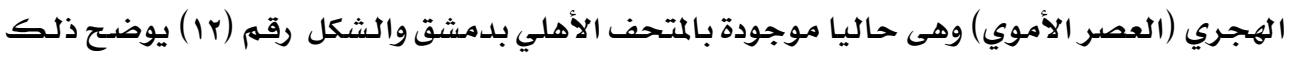

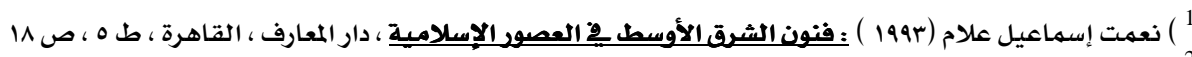

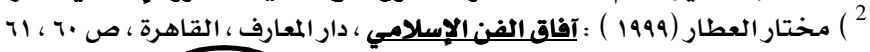




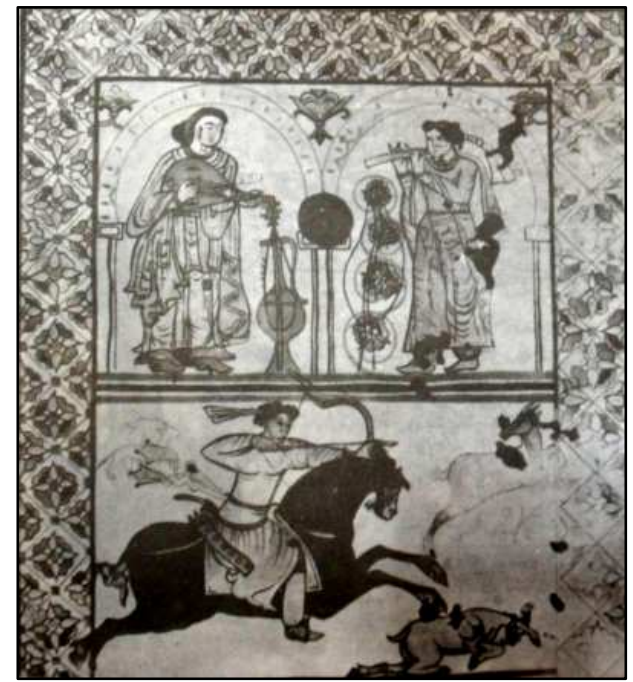

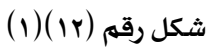

تصوير جداري قصر الحير الغربي القرن الثاني الهجري العصر الأموي ، سوريا - المتحف الأهلي بدمشق.

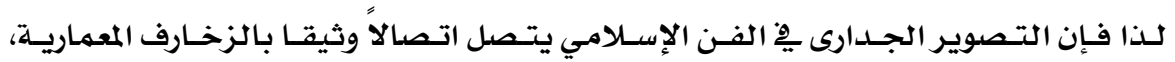

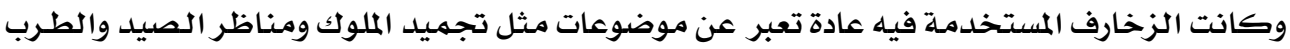

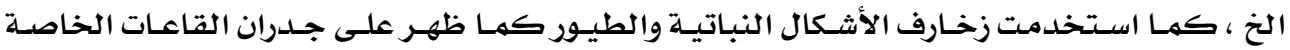

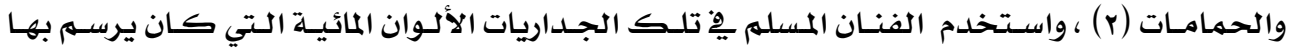

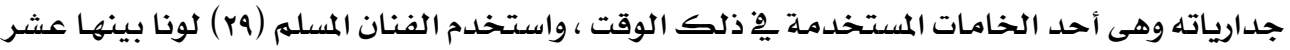

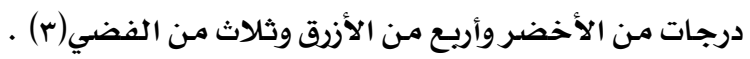

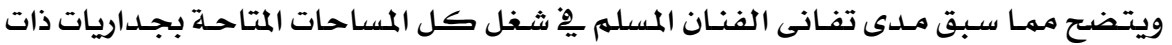

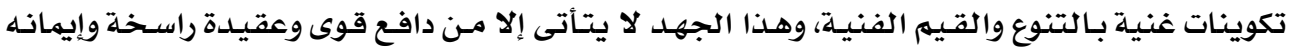

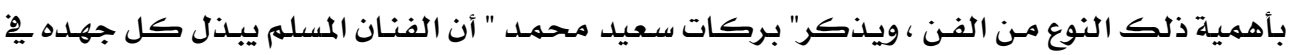

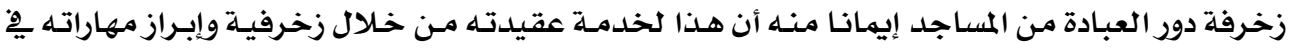

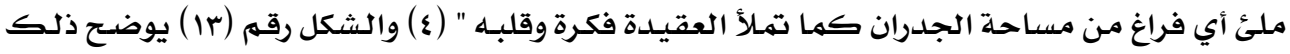

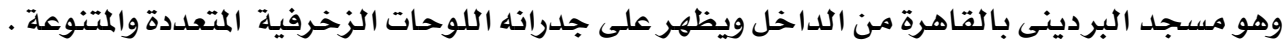

(1) ) نعمت إسماعيل علام ( 1994 ) : فنون الشرق الأوسط 2 العصور الإسلامية ، مرجع سابق ، ص 0؟.

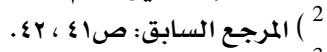

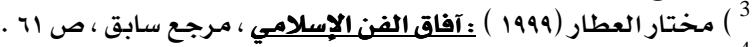

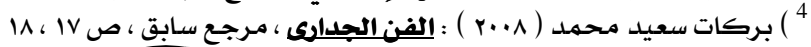




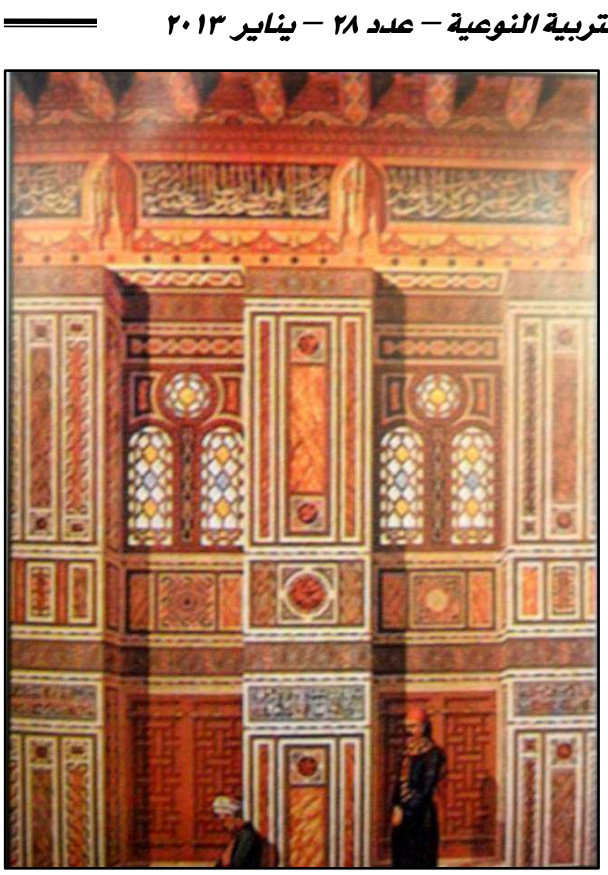

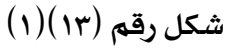 \\ مسجد البرديني بالقاهرة من الداخل ويظهر علي \\ جدرانه اللوحات الزخرفية المتعددة والمتتنوعة.
}

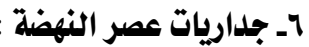

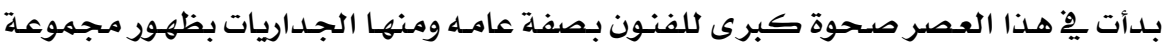

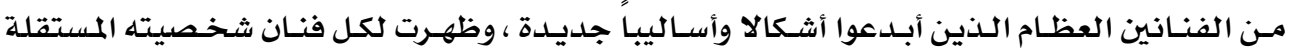

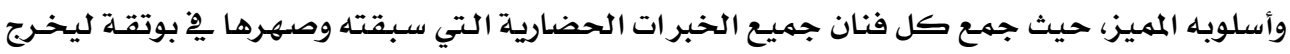
للعالم الأسلوب المميز (r).

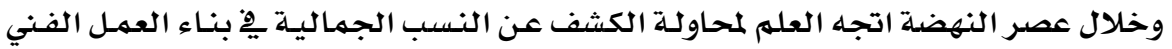

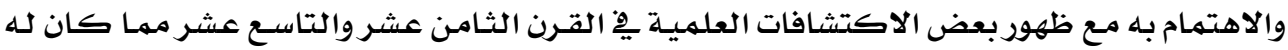

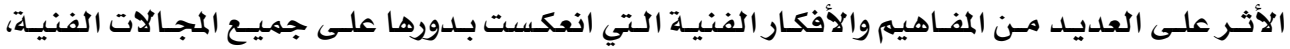

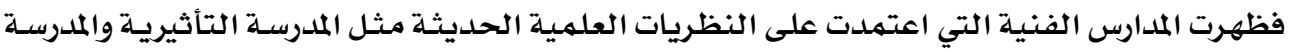

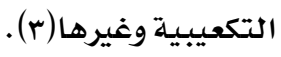

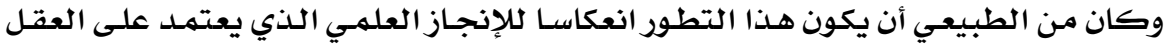

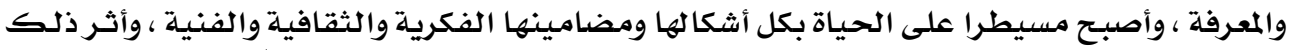

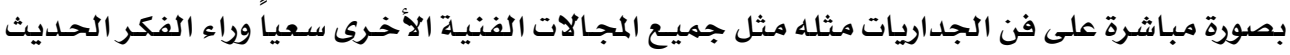

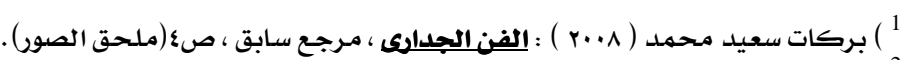

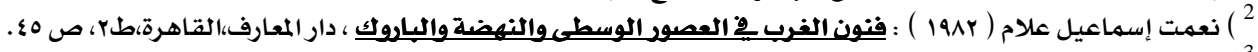


والاستفادة مـن النظريات والاكتشافات العلميـة، وظهور الصناعة وأثرها على المنتجـات بخصائصها

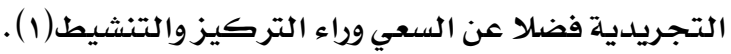

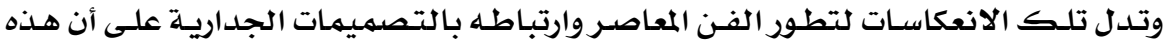

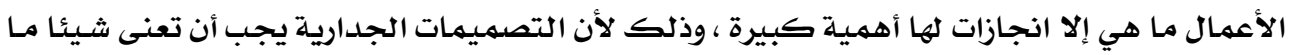

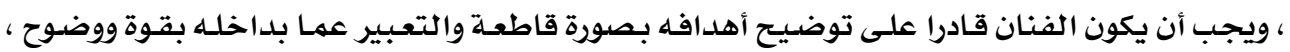

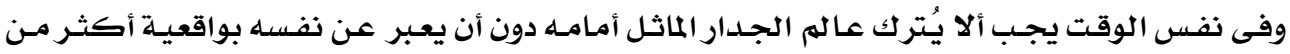

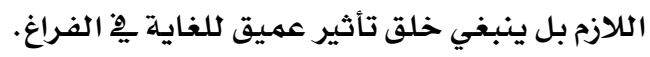

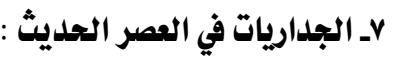
تأثر الفن عقب الحرب العالمية الثانية ومنذ النصف الثاني من القرن العشرين تأثراً كبيرا

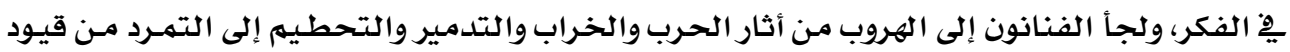

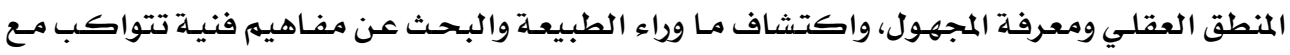

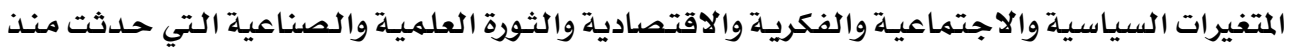

ذلك الحين.) (r)

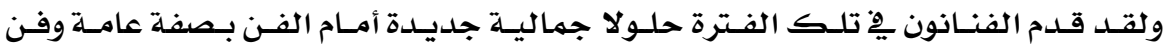

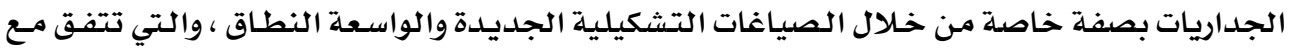

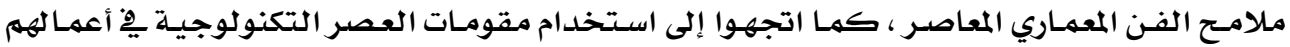

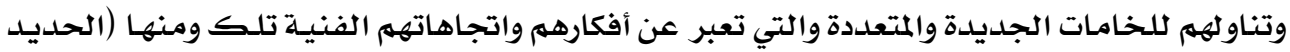

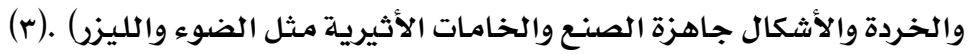

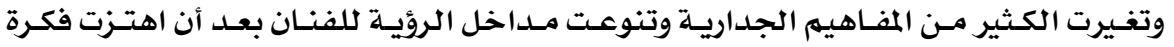

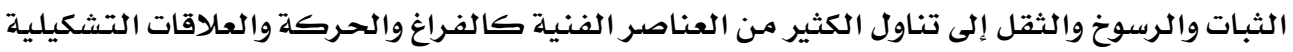

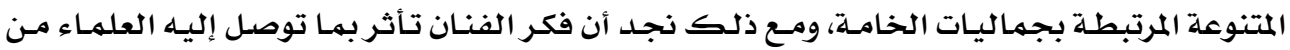

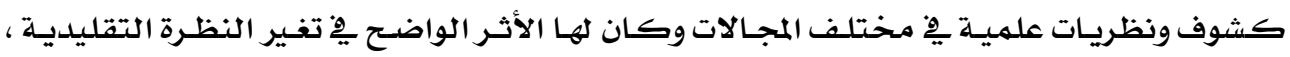

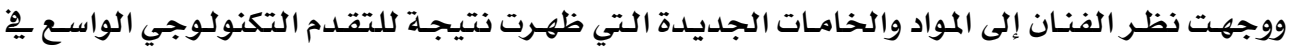

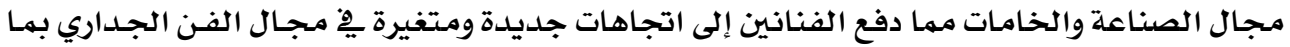

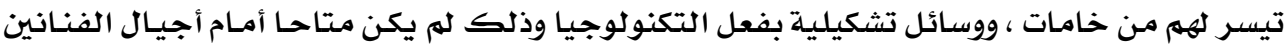

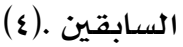

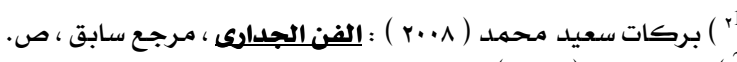

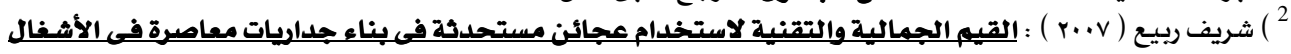

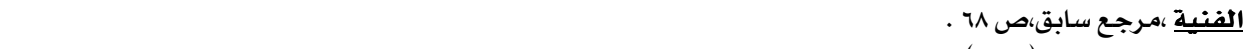

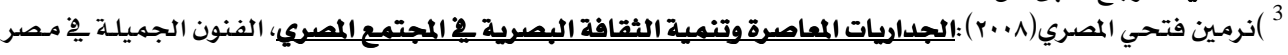

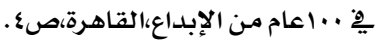

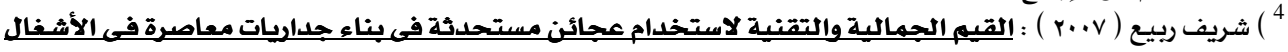

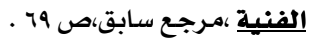


ولقد ظهرت أفكار وفلسفات واكتشافات جعلـت الفنـان الجـداري وأعمانـه ذات سمـات خاصسة والتي ارتبطت باكتشاف العديد مـن الخامـات الحديثة التي لها دور فعال مـع البيئـة المعماريـة والمجتمـع

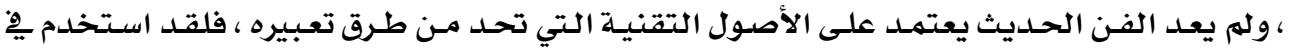
إنتاجه لجداريـاته مواد غريبـة ومتتوعة تخدم أفكاره الفنية وما يهدف إليه من خلال التغـيير ِِّ مفهوم

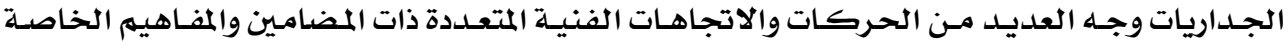
لكل منها وأثر كل منها على الصباغات التشكيلية والأسـاليب التقنية وطرق التنفيذ (1) . وهما سبق نجد أن مفهوم الفن الجداري المعاصـر قد تغير عن المفهوم التقليدي لـه يِّ العصور السـابقة ، حيث تميز باستخدام عدة أشكال مختحلفة مـ الجداريات كالجداريات الحركية أو الضوئية أو الـتي تقـوم على علاقـات بينيـة لأثـكال جـاهزة الــنـع أو الخـردة أو التجميـع والتركيـب أو تحطيم الأثكال المعروضدة ، وإعادة صياغتها تشكيليا مـرة أخرى أو تهثيل الواقع ومحاكاة عناصـر الطبيعية يخ صياغات متعددة ومختلفة ، كمها تبـاينـت أشكال الجـداريات المعاصـرة نظـرا لاختلاف اتجـاهـات وأفكار كل فنان ، كما اعتمد التغيير يِ المفهوم التشكيلي لها على الشكل والمضمون والـصياغة التشكيلية

والخامات المستخدمة وقيمها الجماليـة، والأشكال رقم (ع 10، 10 ) توضح بعضا من تلك الجداريات .

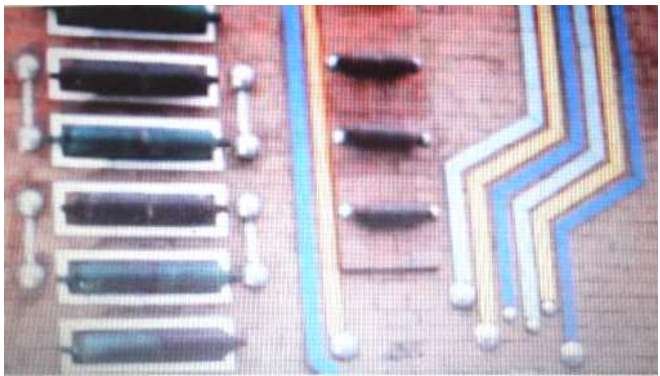

شكل رقم (1)

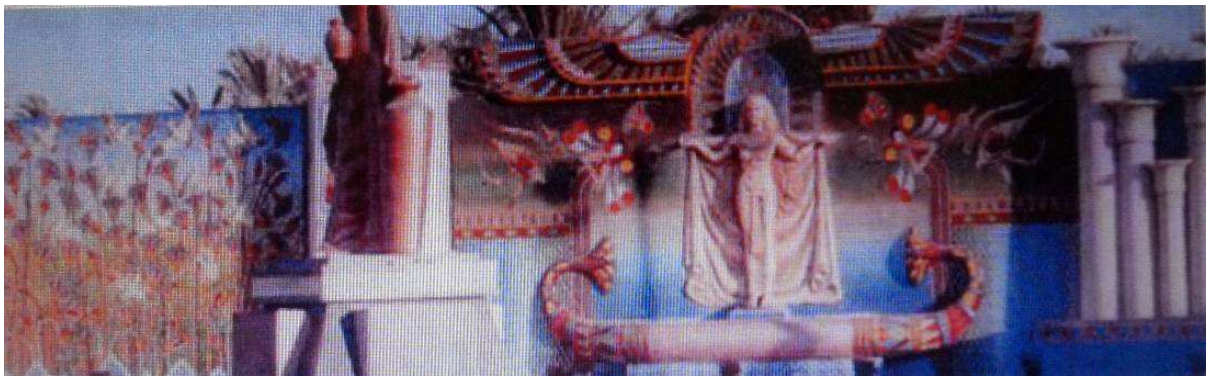

شكل رقم (10)

جزء من جداريه تجمل أحد الأسوار بمحافظة المنيا - فسيفساء ومنحوتات جصية ب...rم.

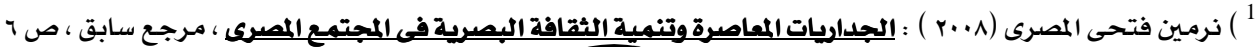




\section{r- الخاهات المستخدهة في تنفيذ اللوحة البدارية :}

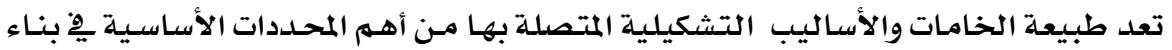

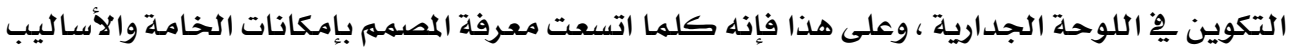

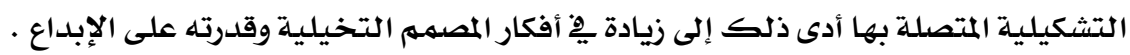

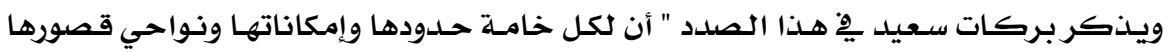
الطبيعية ، وهناك أساليب فنية متعددة لاستخدام أبي خامة فالأسلوب الفني هو الطريقـة التي يتبعها

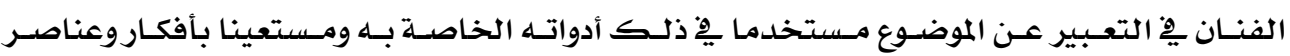

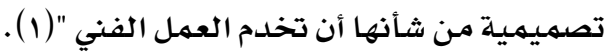

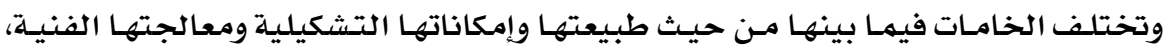

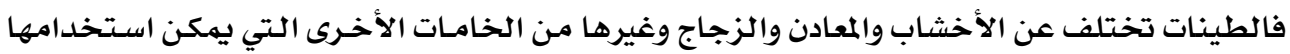

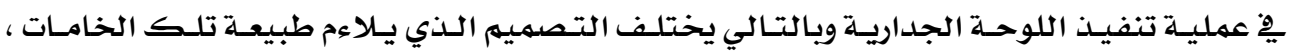

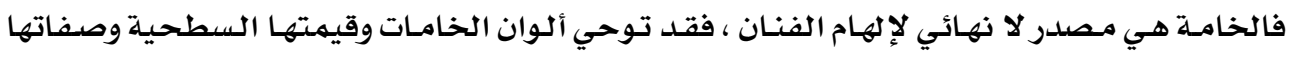

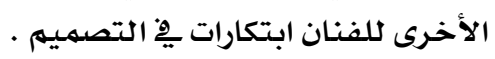

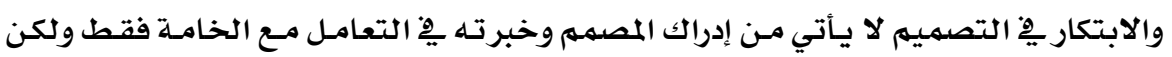

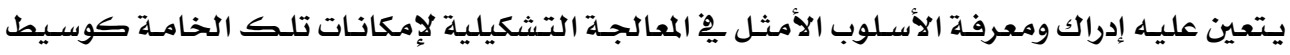

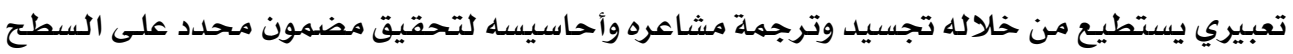

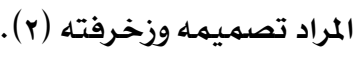

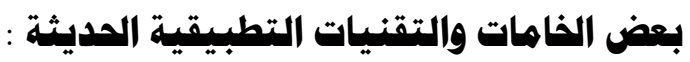
أولا : بعض الخامات التقليدية المستخدمة فى تنفيذ اللوحات الجدارية :

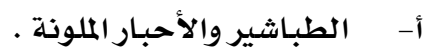

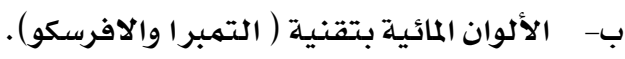

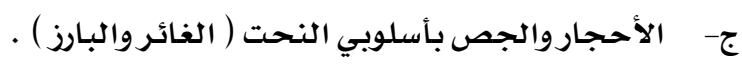

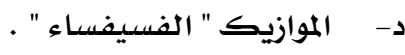

$$
\begin{aligned}
& \text { أـ الطباشير والأحبار الملونة : دوائي }
\end{aligned}
$$$$
\text { الطباشير : }
$$

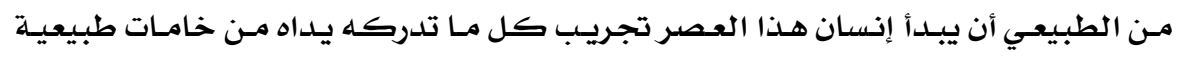

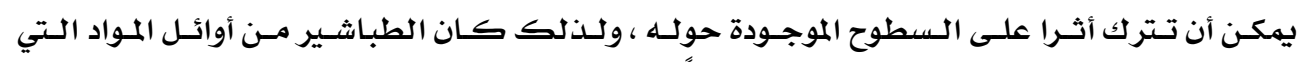

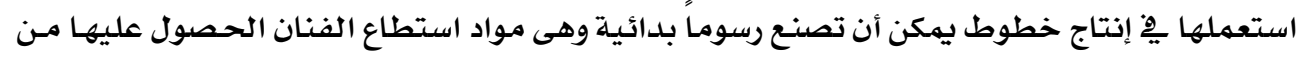

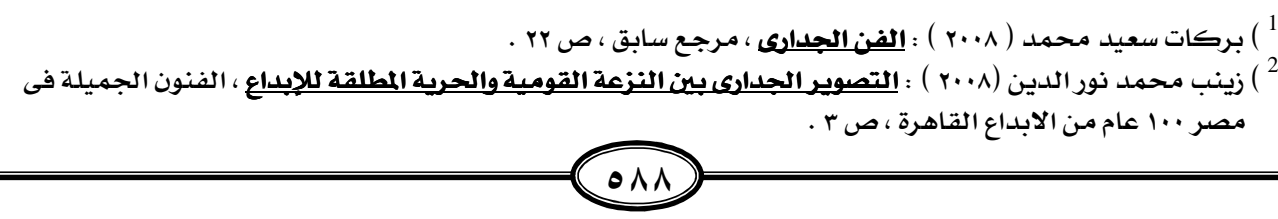




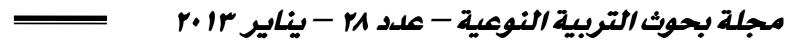

البيئة والأشكال رقم ( IV ، IV ) توضـح استخدام تلك الخامـة وذلك ِِ العصور البدائية وعلى جـدران

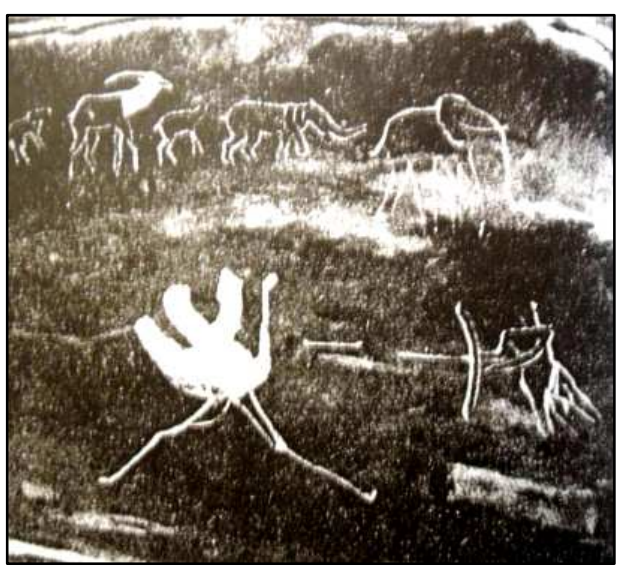

(1) (1)

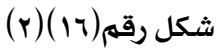

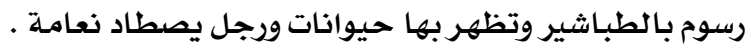

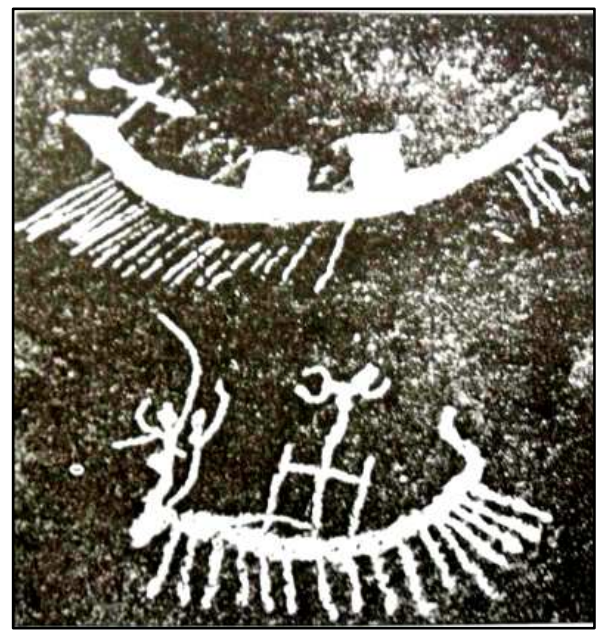

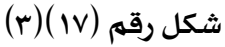

رسوم بالطباشير لنوعين مختليفين من القوارب البدائية.

$\left.{ }^{1}\right)$ Ralf Mayer (1982 ) : Materials And Techniques, ( Op cit . P.333).

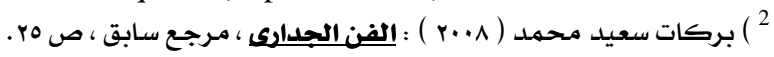

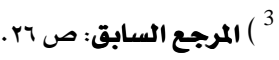


الأحبار الملونة :

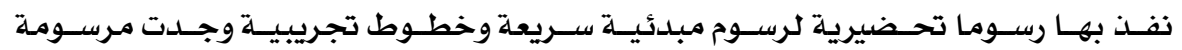

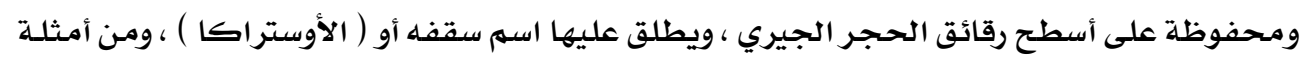

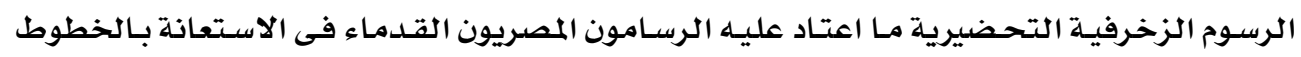

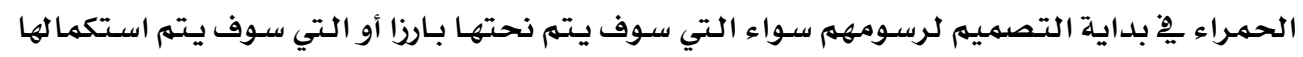
كتصوير جداري ، والشكل رقم (1) يوضح ذلك على جدران مقبرة (نفرحريتاج ) بسقارة وهـو يهثل

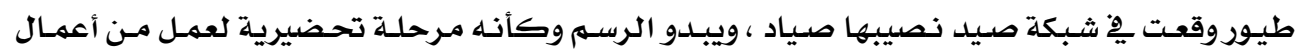
التصوير أو النحت البارز التي كانت ستشكل على نفس الحائط على أسـاس هذا الرسمه (1).

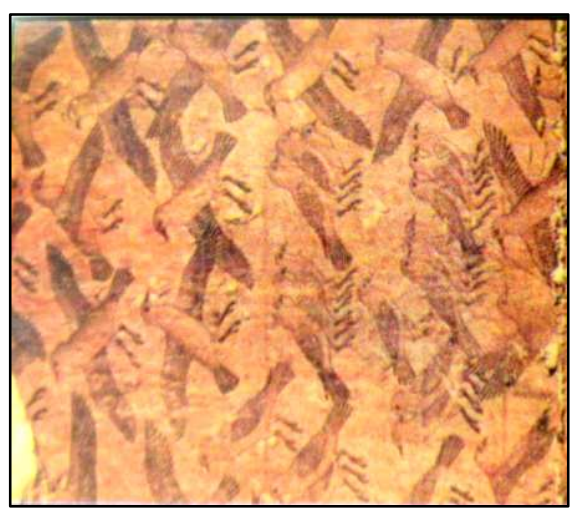

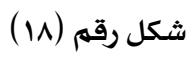

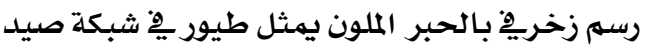

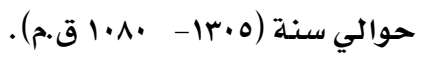

بـ الألوان المائية بتقنية ( الافرسكو والتمبرا ) : الأفرسكو : بلد

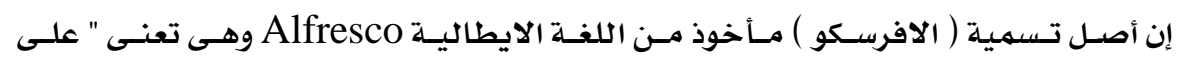

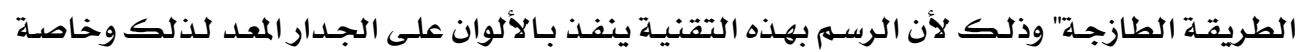
عندما يكون بياضه طازجا أي لهم يجف (؟ ).

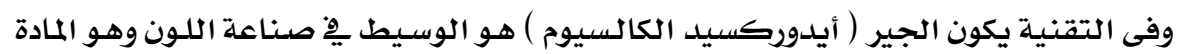

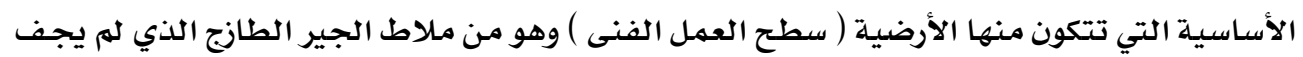

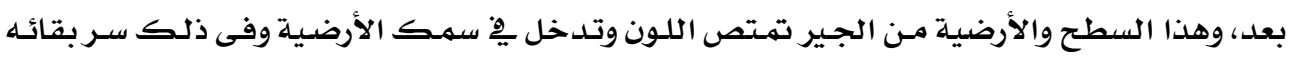
طويلا دون تلف (r).

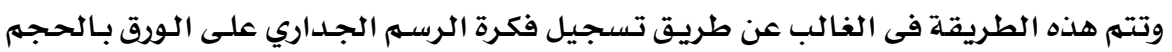

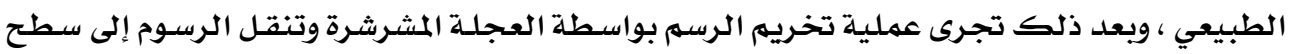

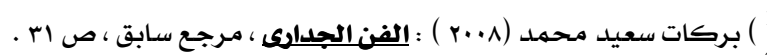

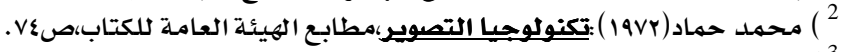




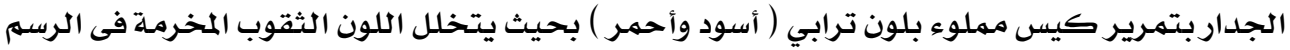

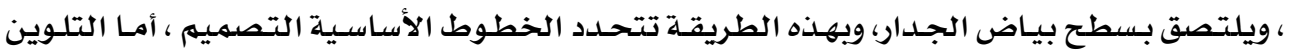

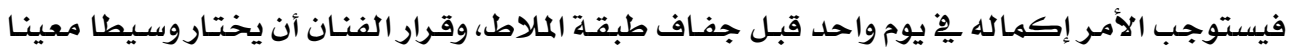

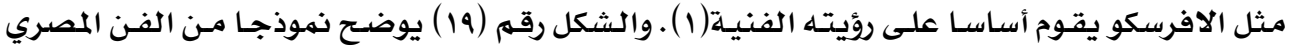

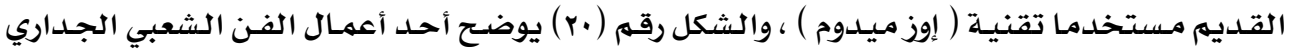

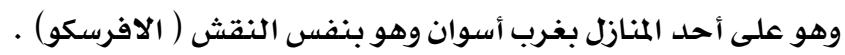

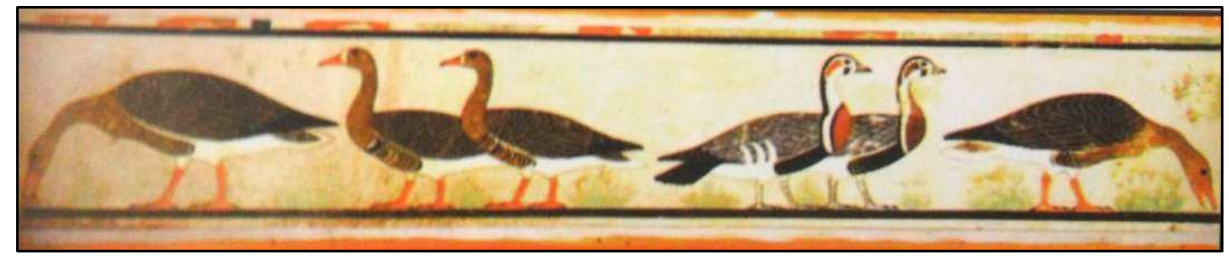

شكل رقم (19)

تصوير بتقنية الإفرسكو يمثل لوحة (اوز ميدوم)

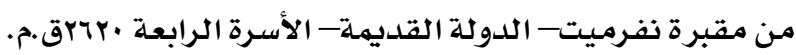

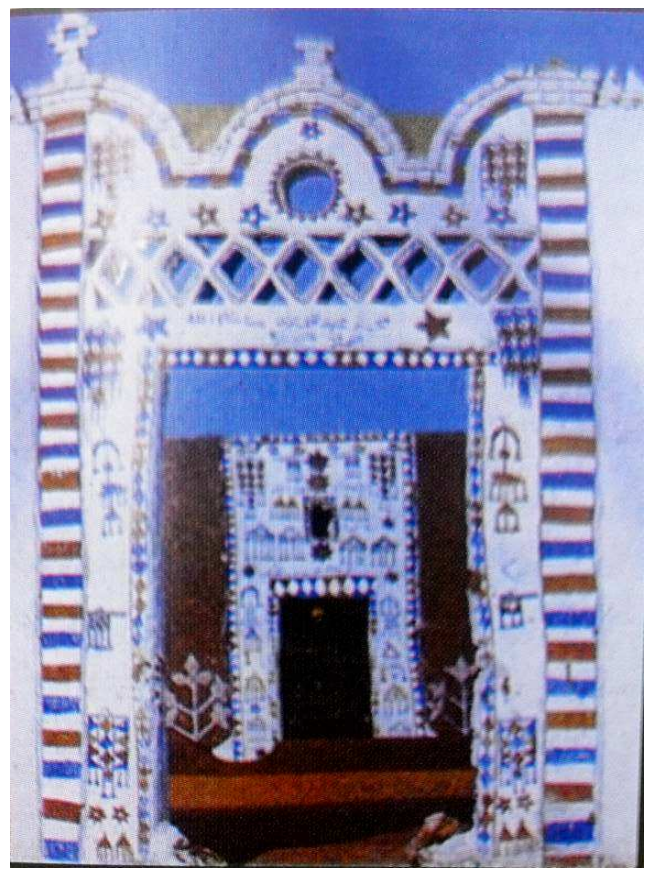

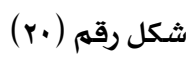

تصوير جداري شعبي بتقنية الإفرسكو

وهو عبارة عن منزل بغرب أسوان.

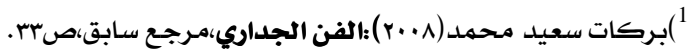




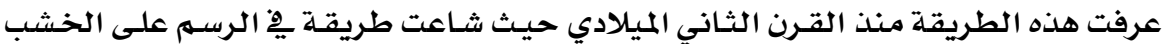

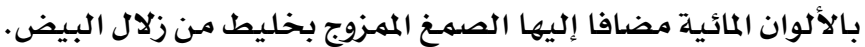

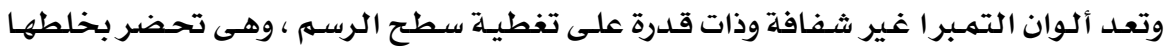

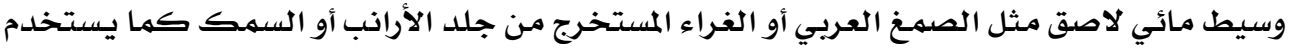

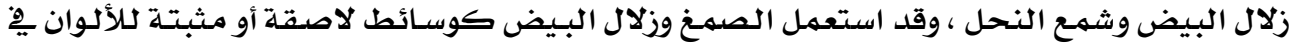

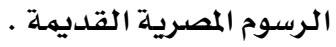

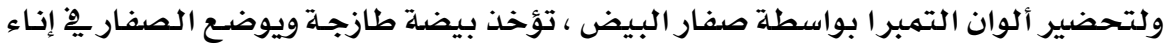

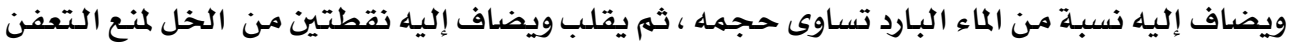

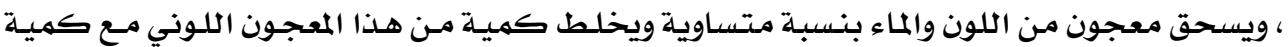

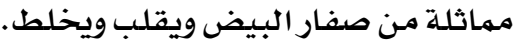

ولقد نفذ بتقنية التمبر ا معظم الصور الحائطية يِّ الفن المسيحي الشرقي ،ووجـد لـه أمثلـة

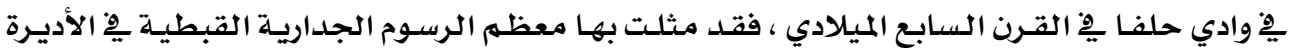

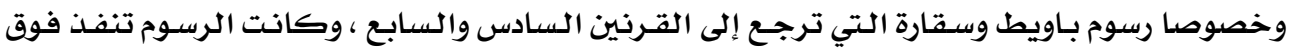

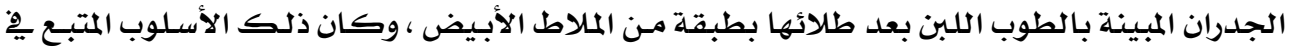

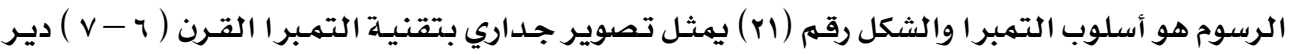

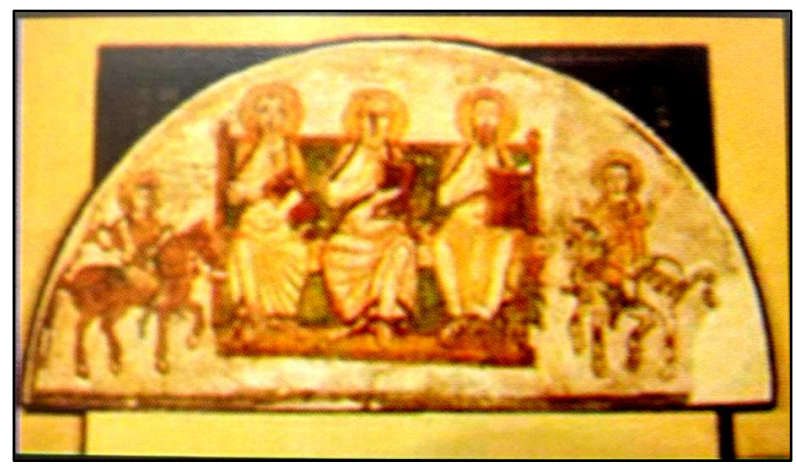
الأنبا أبوللو ببـاويط هو اسلوب التعبر

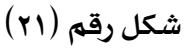
تصوير جداري بتقنية التمبرا القرن(r - v) ديرالأنبا بباويط.

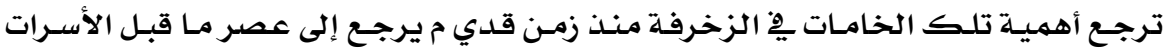

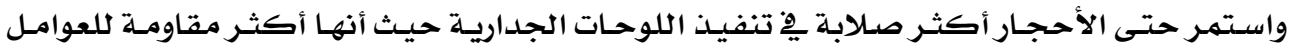

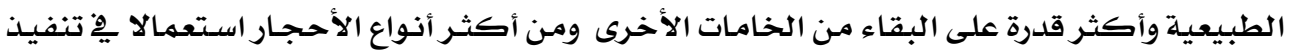

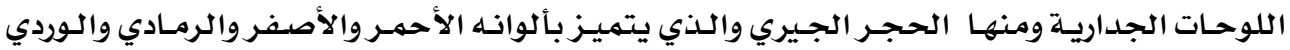

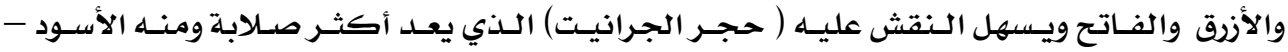




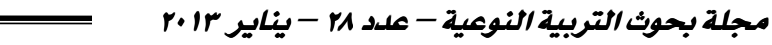

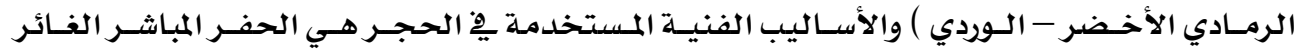

والبارز.) (1)

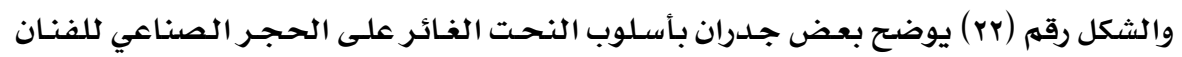

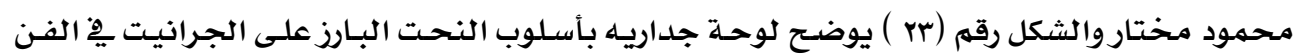

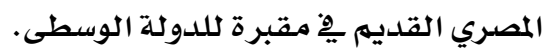

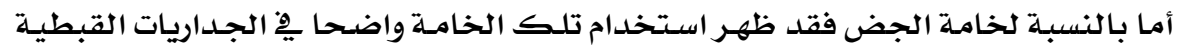

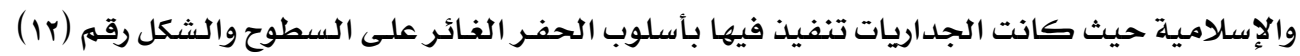

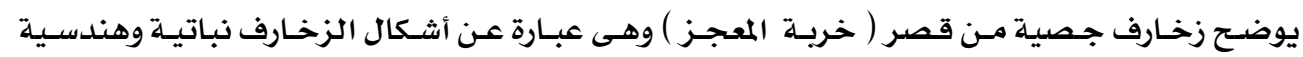

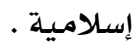

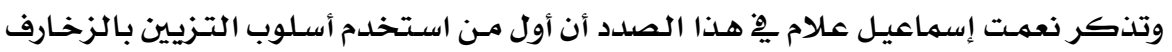

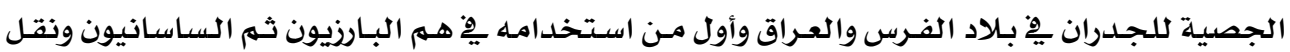

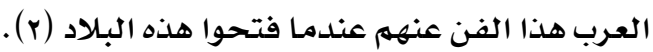

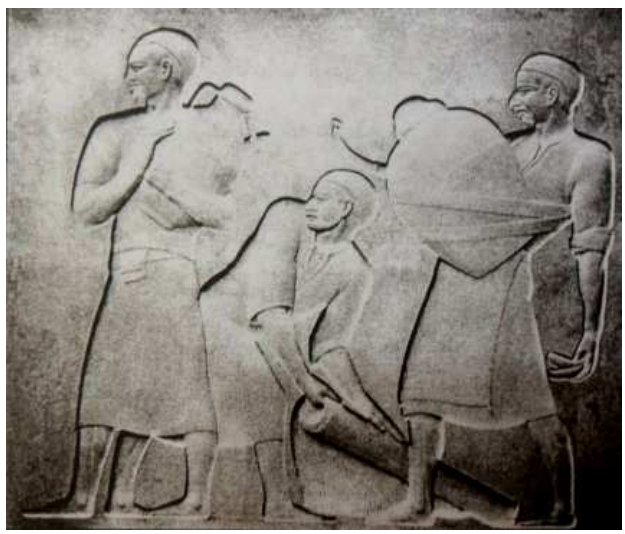

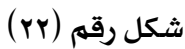

لوحة جداريه بأسلوب النحت الغائر حجر صناعي رباعي

- الفنان محمود مختار.

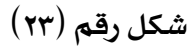

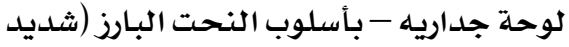

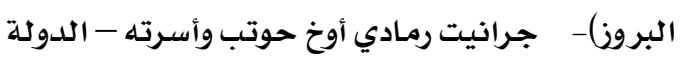

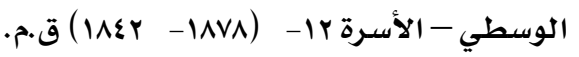

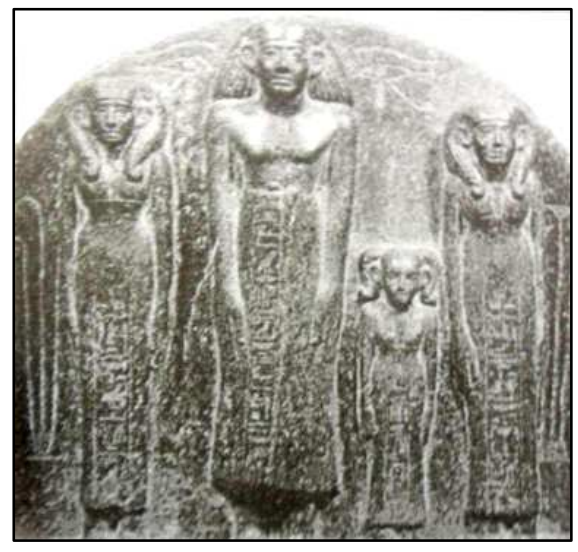

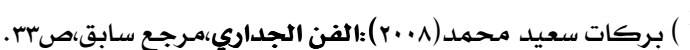

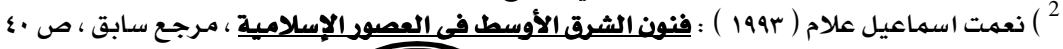


الموزايك أو الفسيفساء هي كلمة مشتقة من اللغة اليونانية والمقصود بها الأثـكال المؤلفـة

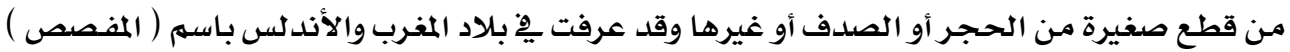

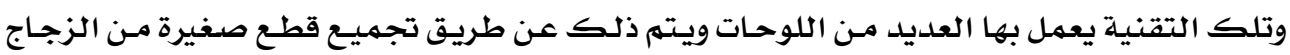

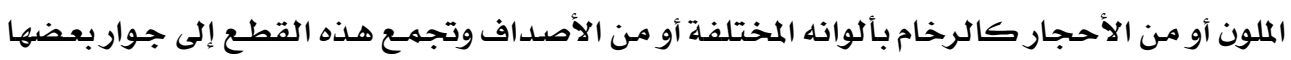

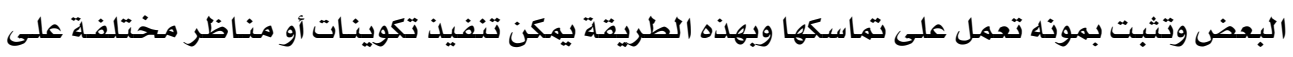

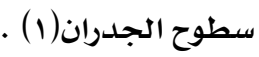

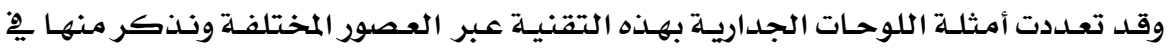

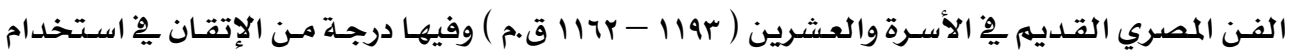

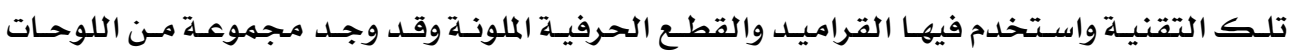

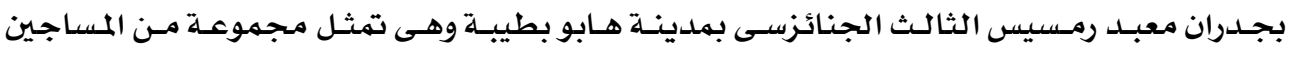

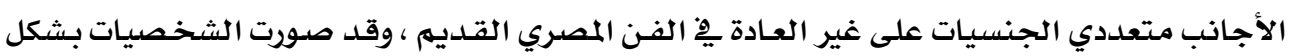

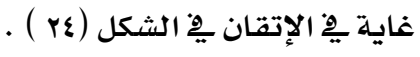

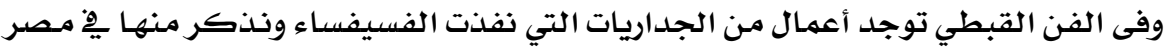

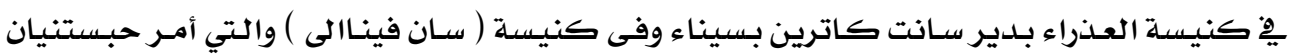

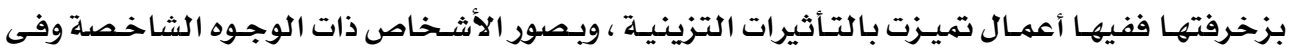

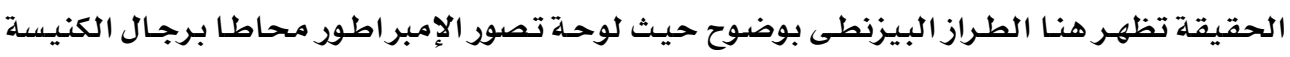

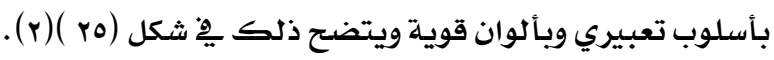

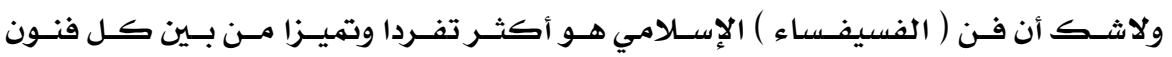

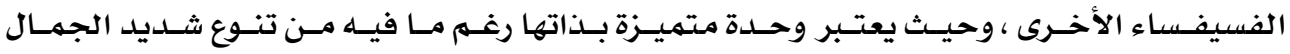

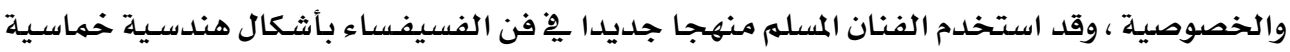

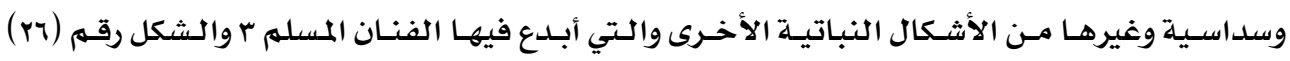

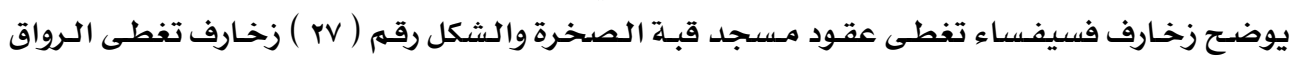

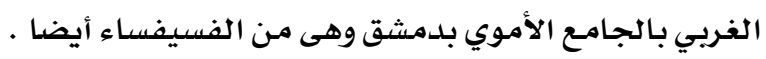

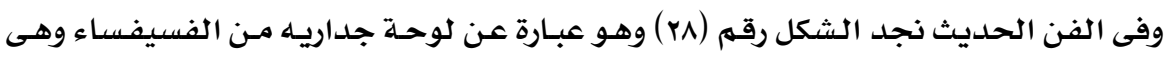

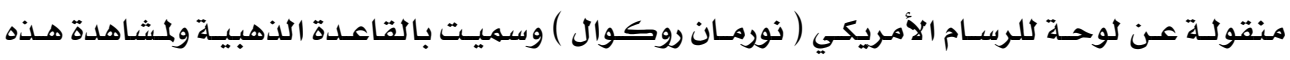

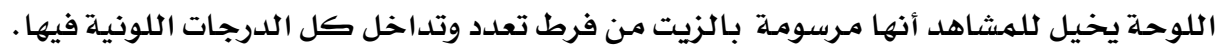

3 ) نعمت اسماعيل علام (1994 ) : فنون الشرق الأوسط فى العصور الإسلامية ، مـرجع سابق ، ص 


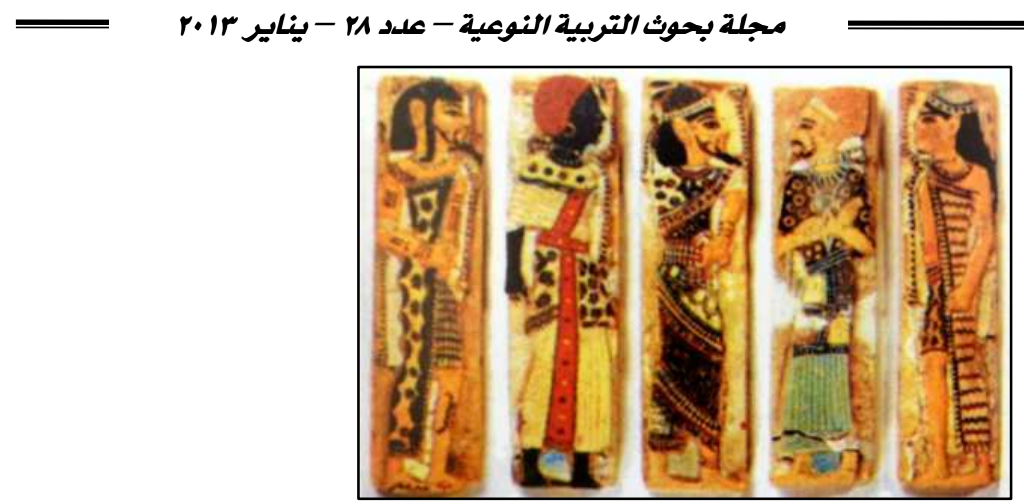

شكل رقم (r)

تصوير جداري بتقنية تشبه تقنية الفسيفساء- لوحة زخرفية من الخزف والقراميد تمثل مجموعة

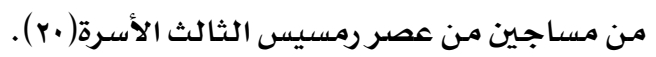

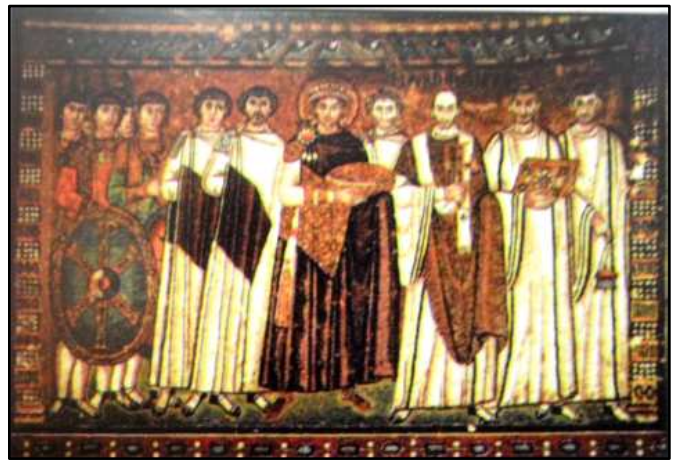

$$
\text { شكل رقمى(ro) }
$$

تصوير جداري بتقنية الفسيفساء يمثل

الإمبر اطور محاطاً برجال الكنيسة الفسئة

كنيسة سان فيتالي( الإمبر مُوم).

\section{شكل رقه(r)}

تصوير جداري بتقنية الفسيفساء تمثل زخارف نباتية

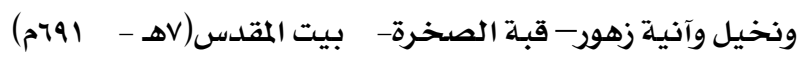

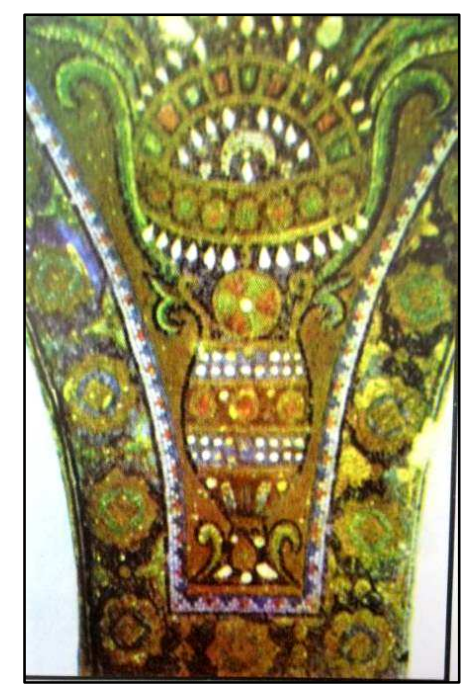




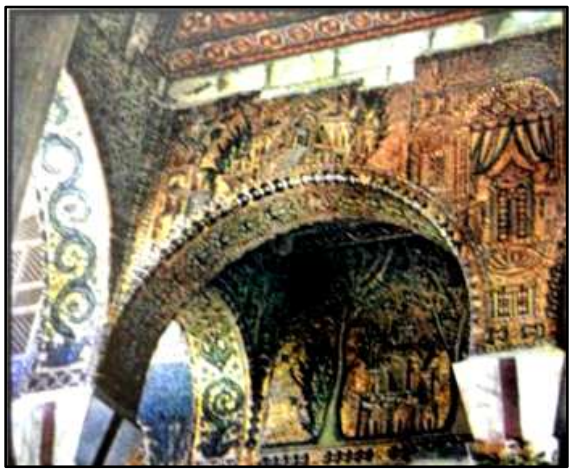

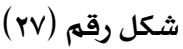

تصوير جداري بتقنية الفسيفساء تمثل نماذج

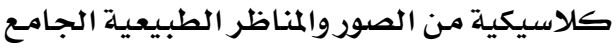

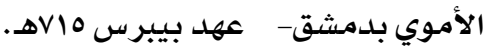

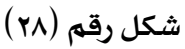

لوحة للرسام الأمريكي(نورمان روكوال)

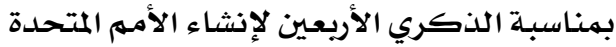

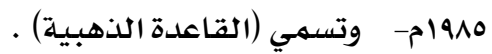

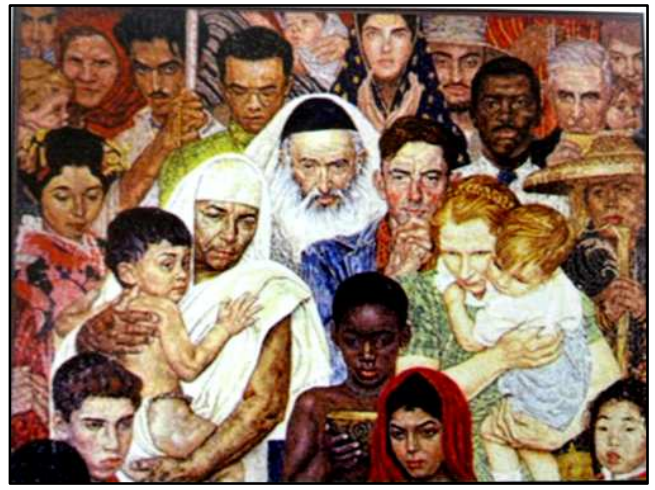

ثانيا : الفاهات والتقنيات التطبيقية المديثة :

تتعدد تلك الخامات ومنها نذكر ما يلي :

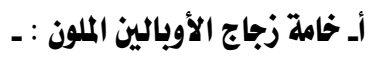

هو نوعية من الزجاج البلوري والذي يعطى انعكاسـا ضوئيا عاليـا كالكريستال ولـه درجـات

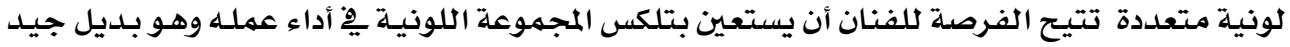

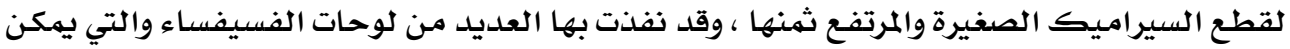

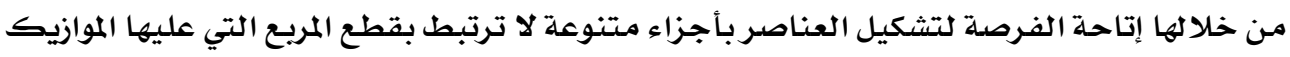

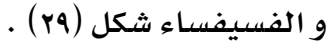




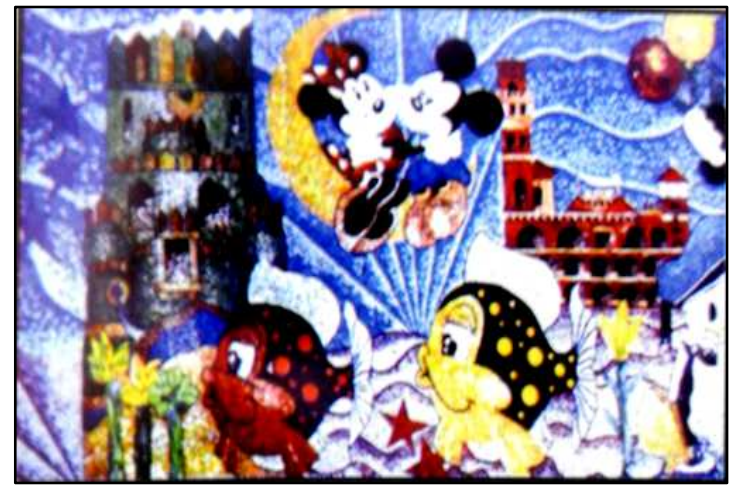

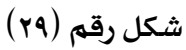

جدارية بقطع زجاج الأوبالين الملون بهساحات مختلفة بأسلوب الفسيفساء منطقة الشاطبي

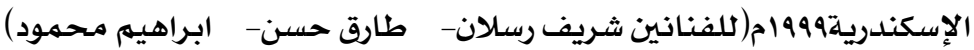
خاهات ( البولى استر - الفوم ) :

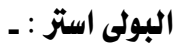

هو من اللدائن الصناعية الحديثة ، وهو مـن الخامـات التي تميزت بسهولة التشكيل وذلك الكا

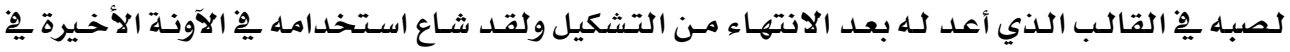

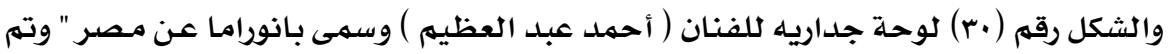

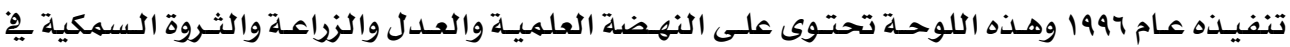

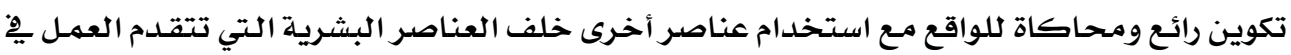

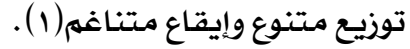

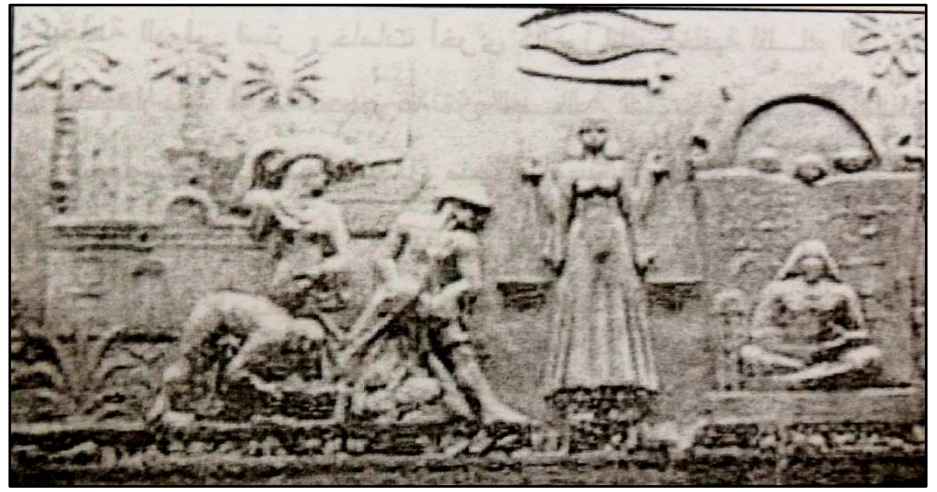

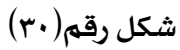
لوحة نحت جداري بخامـة البولي استر - للفنان

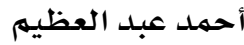

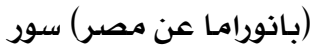

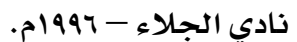

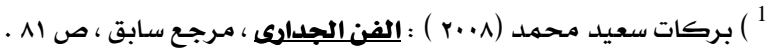


ـ التشكيل الأسمنتى من خلال الفوم :

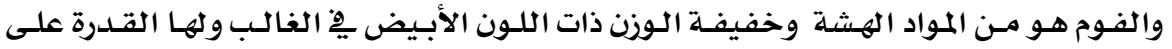

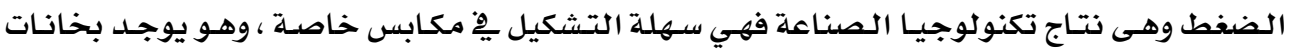

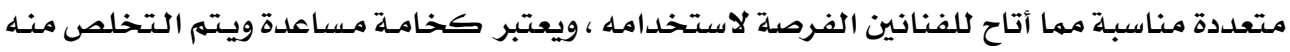

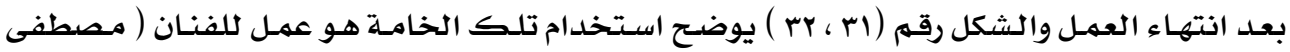

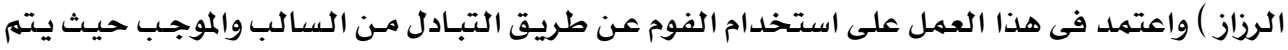

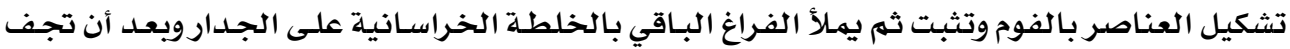

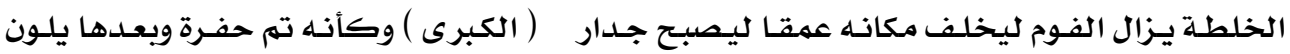

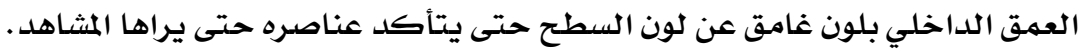

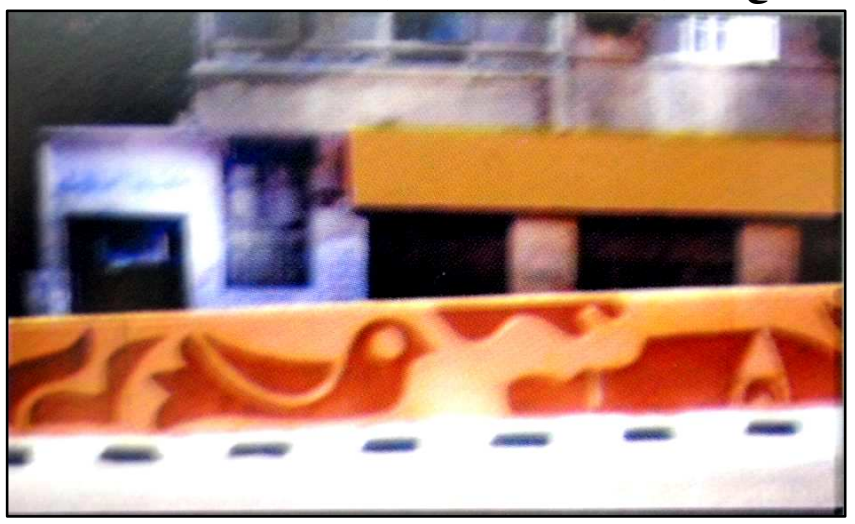

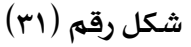

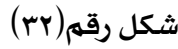

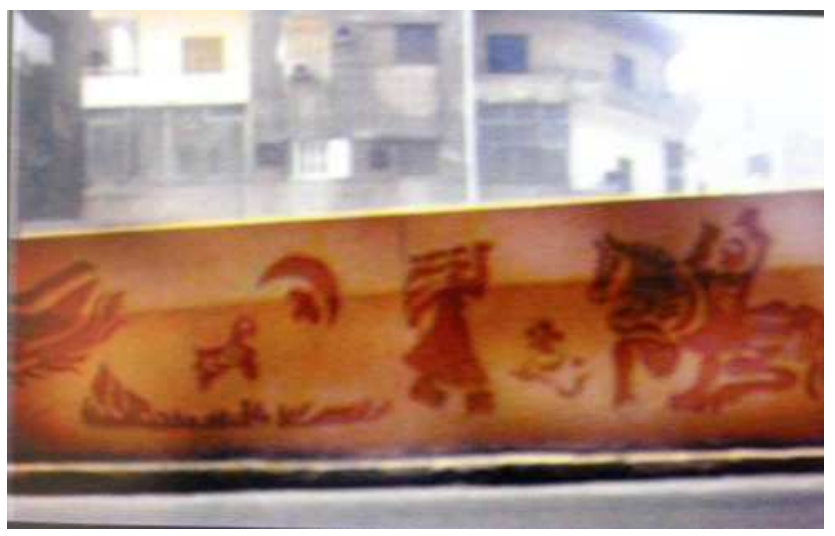

شكل رقم(اr.rr) يمثلان جداريتان نحت غائر للفنان (مصطفي الرزاز) علي الجدران الداخلية والخارجية للكوبري العلوي بالدقي - الجيزة. 


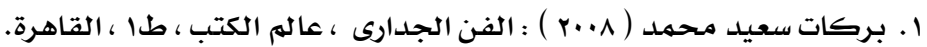

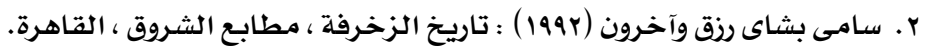

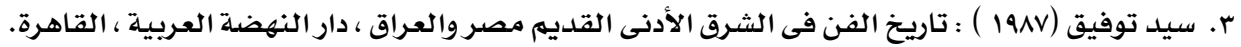

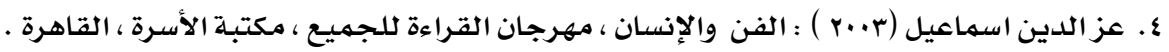

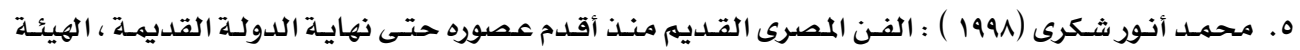
العامـة المصرية للكتاب.

7. محمد حماد (19VY) ): تكنولوجيا التصوير، مطابع الهيئة العامـة المصرية للكتاب. V. مختار العطار (1999 ) : آفاق الفن الإسـلامي ، دار المعارف ، القاهرة. ^. نعمت إسماعيل علام (ب991 ) : فنون الشرق الأوسط يِّ العصور الإسلامية ، دار المعارف ، القاهرة ، ط هـ .

\section{• م البحوث الرسائل العلمية:}

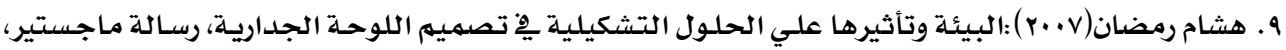

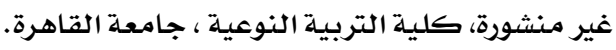

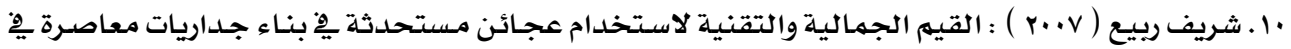

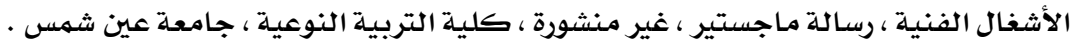

\section{م المجلات والدوريات:}

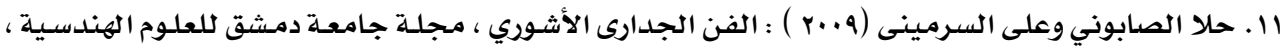

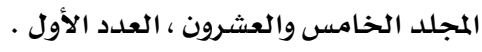

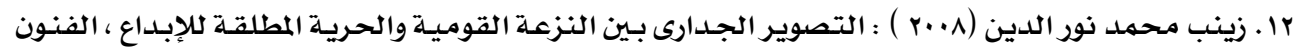

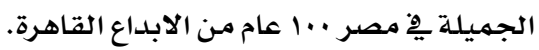

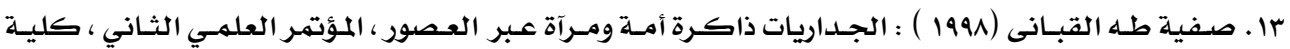
الفنون الجميلة ، جامعة حلوان.

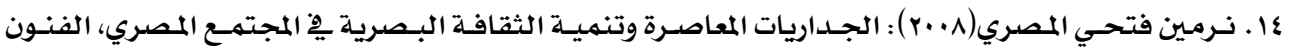

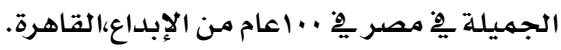

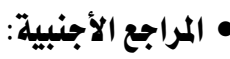

15.Ralf Mayer (1982) : Materials and Techniques, Viking press.

\section{•المواقع على الشبكة اللدولية للمعلومات (الإنترنت):}

16.http://en.wikipedia.org/wiki/Lascaux.

17.http// www_ancientreplicas_com-kingstabbing, lion_jpg.mht.

18.http// www.tronchin.com. 